\title{
The Basic Leucine Zipper Transcription Factor Moatf1 Mediates Oxidative Stress Responses and Is Necessary for Full Virulence of the Rice Blast Fungus Magnaporthe oryzae
}

\author{
Min Guo, Wang Guo, Yue Chen, Suomeng Dong, Xing Zhang, Haifeng Zhang, Wenwen Song, Wei Wang, \\ Qi Wang, Ruili Lv, Zhengguang Zhang, Yuanchao Wang, and Xiaobo Zheng
}

Department of Plant Pathology, College of Plant Protection, Nanjing Agricultural University, Key Laboratory of Monitoring and Management of Crop Diseases and Pest Insects, Ministry of Agriculture, Nanjing 210095, China

Submitted 14 December 2009. Accepted 12 April 2010.

\begin{abstract}
Magnaporthe oryzae is the causal agent of rice blast disease, leading to enormous losses of rice production. Here, we characterized a basic leucine zipper (bZIP) transcription factor, Moatf1, in M. oryzae, a homolog of Schizosaccharomyces pombe ATF/CREB that regulates the oxidative stress response. Moatf1 deletion caused retarded vegetative growth of mycelia, and the Moatf1 mutant exhibited higher sensitivity to hydrogen peroxide $\left(\mathrm{H}_{2} \mathrm{O}_{2}\right)$ than did the wildtype strain. The mutant showed severely reduced activity of extracellular enzymes and transcription level of laccases and peroxidases and exhibited significantly reduced virulence on rice cultivar CO-39. On rice leaf sheath, most of the infectious hyphae of the mutant became swollen and displayed restricted growth in primary infected cells. Defense response was strongly activated in plants infected by the mutant. Diamino benzidine staining revealed an accumulation of $\mathrm{H}_{2} \mathrm{O}_{2}$ around Moatf1 mutant appressoria and rice cells with Moatf1 hyphae that was absent in the wild type. Inhibition of the plant NADPH oxidase by diphenyleneiodonium prevented host-derived $\mathrm{H}_{2} \mathrm{O}_{2}$ accumulation and restored infectious hyphal growth of the mutant in rice cells. Thus, we conclude that Moatf1 is necessary for full virulence of $M$. oryzae by regulating the transcription of laccases and peroxidases to impair reactive oxygen speciesmediated plant defense.
\end{abstract}

Reactive oxygen species (ROS), including superoxide $\left(\mathrm{O}^{2-}\right)$ and hydrogen peroxide $\left(\mathrm{H}_{2} \mathrm{O}_{2}\right)$, generated by specific NADPH oxidases are regarded as inevitable harmful by-products of aerobic metabolism (Apel and Hirt 2004). The produced ROS play key roles in both defense and cellular differentiation processes in plants, animals, and fungi (Aguirre et al. 2005; Bedard and Krause 2007; Takemoto et al. 2007; Torres et al. 2005). For example, ROS are involved in redox-dependent regulation of different cellular functions, including energy metabolism and the response to stress or growth signals. In plants, ROS accumulation at the site of pathogen invasion has an antimicro-

Corresponding author: Z. Zhang; E-mail: zhgzhang@njau.edu.cn; Telephone: +1 86-25-84396972; Fax: +1 86-25-84395325.

* The $\boldsymbol{e}$-Xtra logo stands for "electronic extra" and indicates that five supplementary figures and one supplementary table are published online and that Figures 4, 9, and 10 appear in color online. bial, cell-wall strengthening, or signaling role (Lamb and Dixon 1997; Mellersh et al. 2002; Torres et al. 2005). Excessive ROS accumulation can oxidize cell components such as DNA, protein, and lipids, thus damaging cell organelles and affecting cell function (Skamnioti et al. 2007). However, to survive and colonize under these harsh conditions, pathogens have evolved various strategies to detoxify ROS during plant-pathogen interactions. Studies have proposed that detoxifying enzymes that are preformed or inducible or both, including superoxide dismutase, catalases, and peroxidases, likely contribute to fungal ROS tolerance (Kawasaki et al. 1997; Lanfranco et al. 2005; Molina and Kahmann 2007; Navarro et al. 1996). Moreover, some evidence suggests that plant cells are able to initiate an oxidative burst to prevent pathogen invasion (Auh and Murphy 1995; Doke 1983; Grant and Loake 2000). The plant NADPH oxidases known as respiratory burst homologs (Rboh) are responsible for ROS production associated with plant defense responses (Doke 1985; Simon-Plas et al. 2002; Torres et al. 2002; Yoshioka et al. 2003). During plant-microbe interactions, production of $\mathrm{H}_{2} \mathrm{O}_{2}$ by such plasma membrane NADPH oxidases can induce a hypersensitive reaction in host plants, leading to programmed cell death and cellular defense against pathogen attack. In rice, the membrane OsRac1 GTPase complex, correlated with OsrbohB, controls ROS generation by direct regulation of NADPH oxidase (Ono et al. 2001; Wong et al. 2007). In Nicotiana benthamiana, virus-induced gene silencing of two homologs of gp91phox, rbohA and $\operatorname{rbohB}$, was found to reduce ROS production and decrease resistance to infection by Phytophthora infestans (Yoshioka et al. 2003). Similarly, in animals, pathogen attack generally results in ROS accumulation and triggers innate immunity (Giles et al. 2006). Taken together, these results indicate that ROS production plays a key role in counteracting pathogen invasion in defense responses.

As for plant pathogens, they are well-known to be capable of overcoming defense mechanisms of plants in the course of a compatible interaction. Recently, studies on an AP-1-like transcription factor from the maize pathogen Ustilago maydis suggested that peroxidases in the pathogens are likely involved in detoxifying host-driven ROS and help phytopathogens successfully invade host tissues (Molina and Kahmann 2007). In Cochliobolus heterostrophus, deletion of the yap1-homologous gene Chapl shows no effect on virulence but displays high sensitivity to oxidative stress (Lev et al. 2005). In Claviceps purpurea, deletion of transcriptional factor CPTF1, a homolog of ATF/CREB in mammals, leads to increased $\mathrm{H}_{2} \mathrm{O}_{2}$ accumula- 
tion at the infection site, enhanced defense reactions of the plant during infection, and reduced virulence to rye (Nathues et al. 2004). In Magnaporthe oryzae, a novel gene, DES1, affecting expression of several groups of peroxidase and laccase genes, participates in detoxifying ROS at the attempted invasion site, and the des 1 deletion mutant loses the ability to cause rice disease (Chi et al. 2009). These results further demonstrate the need for phytopathogens to detoxify host-derived ROS at the infection site to successfully invade the host. Thus, research on mechanisms of how phytopathogens avoid ROSmediated host defenses could help to elucidate molecular aspects of pathogenicity.

$M$. oryzae is the causal agent of rice blast disease, the most severe infection of cultivated rice (Oryza sativa) and a major constraint on worldwide rice production (Talbot 2003). It has become an ideal model to study filamentous fungal pathogenplant interactions due to the molecular and genetic tractability of both the fungus and the host (Talbot 2003). In field conditions, mature conidia adhere to rice leaves with the help of mucilage secreted at the conidial tip (Hamer et al. 1988). Then, the dome-shaped cells, differentiated from the end of germ tubes, help to penetrate the plant cuticle and enter the internal plant tissues (Howard et al. 1991). After colonization, newly formed conidia are released from the blast lesions to initiate further infection cycles. As a result, the disease can spread rapidly and cause great losses in rice production. Previously, great efforts were made to control the disease using chemical fungicides, but the results were not satisfactory. Recently, the release of the $M$. oryzae complete genome sequence facilitates the discovery of pathogenicity-related genes at the genome scale during infection, enhances understanding of its pathogenicity mechanisms, and allows us to plan new disease control strategies.

In this study, we identified a gene, Moatfl, homologous to basic leucine zipper (bZIP) transcriptional factor ATF/CREB from yeasts to mammals, in the genome sequence of $M$. oryzae. Multiple alignment analyses showed that this homology is predominantly at the C-terminal bZIP domain. Our results indicate that Moatfl plays an important role in growth under oxidative stress conditions and is required for full virulence of $M$. oryzae.

\section{RESULTS}

\section{Moatf1 is an ATF/CREB homolog in M. oryzae.}

A search for genes encoding transcriptional regulators from the $M$. oryzae genome database (Dean et al. 2005) was performed, and a putative bZIP-type protein-encoding gene similar to ATF/CREB, which we named Moatf1, was identified in locus MGG_08212.6, with an open reading frame (ORF) of 526 amino acids interrupted by two introns. In the $\mathrm{C}$ terminal, a highly conserved bZIP domain consisting of a basic region involved in DNA binding and a neighboring leucine zipper that participates in dimerization presents from position 405 to 471 (Fig. 1A and B). In mammals, ATF/CREB is deemed to be involved in responses to different environmental stimuli and oxidative stress. Comparison of the conserved bZIP domain in ATF/CREB sequences from mammals to fungi showed that the bZIP domain in Moatf1 is highly similar to that in other filamentous fungi, with a Q-rich region in the middle of the bZIP domain and a conserved L-rich region covering the full bZIP domain (Fig. 1B). The phylogenetic tree based on the full sequence comparison of ATF/CREB from different organisms revealed that the Moatf1 sequence is distant from the animal sequences and most similar to sequences from Ascomycete fungi, including Neurospora crassa (XP_961431), Aspergillus clavatus (XP_001271133), and the plant pathogen Sclerotinia sclerotiorum (XP_001593486) (Fig. 1C).

\section{Moatf1 is strongly activated}

during conidiation and initial infection in planta.

To gain insights into the possible function of Moatfl in $M$. oryzae, we first examined the transcript abundance of Moatfl in diverse fungal developmental stages. Relative abundance of Moatf1 mRNA transcripts during vegetative growth, conidiation, and plant colonization were estimated by quantitative real-time polymerase chain reaction (qRT-PCR) (Fig. 2A). The abundance of Moatfl transcripts during vegetative growth in liquid complete media $(\mathrm{CM})$ was extremely low compared with the stableexpression actin gene (MGG_03982.5) in M. oryzae (average delta cycle threshold $[\mathrm{Ct}]=7 . \overline{7})$. But interestingly, in the course of initial invasive growth in planta, the mRNA accumulation of Moatfl increased almost sevenfold at $8 \mathrm{~h}$ postinoculation (hpi) on rice leaves, compared with that of conidia ( $0 \mathrm{hpi})$, and the transcript abundance continued to increase during the infection timecourse and reached almost 13 -fold at $24 \mathrm{hpi}$, and declined thereafter, with fourfold at $48 \mathrm{hpi}$ and threefold at $72 \mathrm{hpi}$, compared with that at conidia stage, indicating that Moatfl transcript is strongly activated during initial infection in planta.

\section{Targeted gene deletion generates the Moatf1 mutants.}

To elucidate the function of Moatfl in M. oryzae, a deletion plasmid flanking approximately $1 \mathrm{~kb}$ up- or downstream, or both, of the Moatfl coding region was constructed (Fig. 2B). Moatfl deletion mutants were generated by replacing the Moatfl ORF with a selective marker, the hygromycin phosphotransferase B gene, through transformation of protoplasts of the rice pathogenic strain Guy11 with linear DNA fragments amplified from the plasmid pMD-Moatfl-HPH. The hygromycinresistant transformants were first selected on complete media supplemented with hygromycin $\mathrm{B}$, and the polymerase chain reaction (PCR) was then used to screen for putative deletion mutants by verification of genomic DNA of the transformants (data not show). Complete inactivation of Moatf1 transcription in the deletion mutants was verified by reverse transcription (RT)-PCR using the RNA samples extracted from the mycelium (Fig. 2C). The putative deletion transformants were further confirmed by Southern hybridization, to demonstrate the deletion of the Moatfl ORF region and the addition of a singlecopy integration of the $H P H$ gene (Fig. 2D). Furthermore, a complementation strain Moatf1/ATF1 was created by reintroducing the ORF sequence of Moatfl under control of the TrpC promoter, according to Zhang and associates (2009) (Fig. 2C).

\section{Moatf1 deletion leads to retarded vegetative growth.}

To investigate the role of Moatfl on mycelium growth in $M$. oryzae, we simultaneously incubated the Moatfl mutant, the wild-type strain Guy11, and complemented strain Moatf1/ATF1 on $\mathrm{CM}$ and minimal media (MM) and compared their growth responses. Mycelial growth of the Moatf1 mutant differed from that of the wild-type strain Guy11 and complemented strain Moatf1/ATF1 on these two artificial nutrient media. On CM medium, the wild-type strain Guy11 grew much faster than the Moatfl mutant (Fig. 3A), whereas aerial hyphae of the Moatfl mutant became sparse and thinner on CM medium compared with those of Guy11 (Fig. 3C). Furthermore, the dry weight of hyphae of the Moatfl mutant was lower than that of Guy11 when cultured in liquid CM medium (data not shown). Similarly, after incubation on MM medium for 4 days, colony expansion of the Moatf1 mutant was slower than that of Guy11 and complemented strain Moatf1/ATF1 as compared with growth on CM medium (Fig. 3B). However, the Moatfl mutant resumed normal aerial hyphal growth on MM medium, in contrast to the sparse aerial hyphae observed on CM medium (data not show). The morphology of conidia did not exhibit obvious differences between the Moatfl mutant and the wild-type 
strain Guy11. The Moatf1 mutant and wild-type Guy11 shared the same conidial adhesion and germination rate (data not shown).

\section{Moatf1 deletion attenuates the virulence of $M$. oryzae.}

To determine whether Moatfl is involved in pathogenicity, conidial suspensions $\left(1 \times 10^{5}\right.$ conidia/ml $)$ of both the Moatfl mutant and wild-type strain Guy11 were sprayed onto 4-weekold susceptible rice seedlings (Oryza sativa cv. CO-39) to develop blast lesions. By 5 days after inoculation, symptoms on rice leaves had fully emerged, and the Moatfl mutant was found to be less pathogenic than Guy11. The Moatfl mutant developed restricted resistant-type lesions on rice compared with Guy11, which caused spreading lesions. The estimated disease lesion area caused by the Moatf1 mutant occupied 47\% less of the leaf surface than the lesion area caused by the wildtype strain Guy11 (Fig. 4A and B). The attenuated virulence of the Moatfl mutant strain could be complemented and full virulence restored by reintroducing the Moatfl gene. These data suggest that Moatfl is required for full virulence of $M$. oryzae.

\section{Moatf1 deletion led}

to the retarded growth of infectious hyphae.

To further elucidate the mechanism of attenuated virulence of the Moatf1 mutant, we first examined appressorium turgor of conidia, but no obvious defects were observed during appressorium development in the Moatfl mutant and no evident dif-

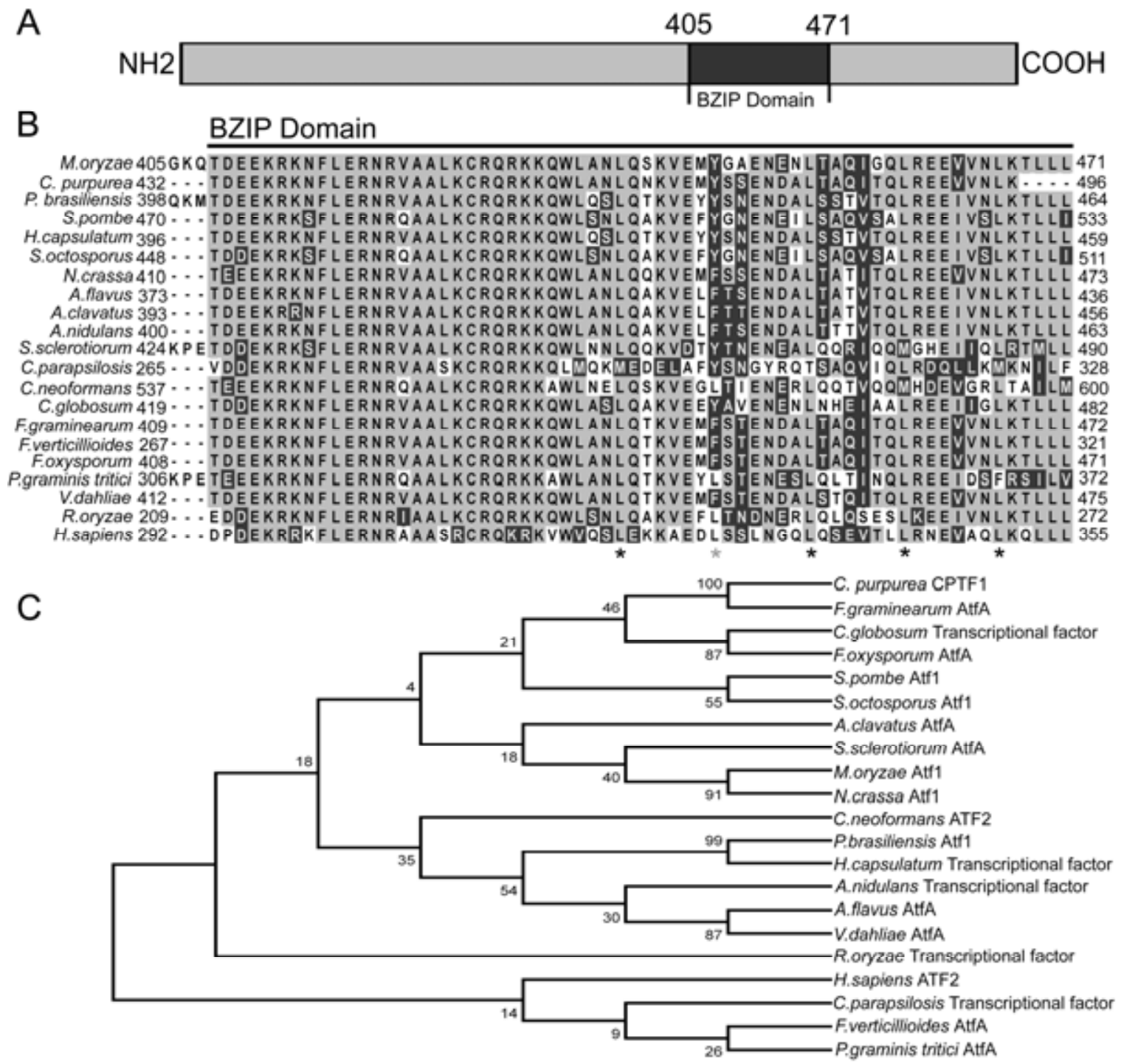

Fig. 1. Functional domain comparisons of atf1 in different organisms. A, Physical map of Moatf1 showing a conserved functional domain, a basic leucine zipper (bZIP) starting at amino acid 405 and ending at amino acid 471. B, Alignment of the bZIP domain of Moatf1 from Magnaporthe oryzae with those from other organisms was performed using the Clustal_W program. Conserved leucine residues are indicated by asterisks at the bottom, the gray asterisk represents missing leucine residues in Moatf1. Identical amino-acid residues are highlighted with dark gray background, close similar amino-acid residues are shaded with light gray, and distant similar amino acids are not shaded. C, A phylogenetic tree of Moatfl, generated by the Mega 3.0 Beta program, with 500 bootstraps based on alignment of the full sequences of ATF/CREB families from fungi yeast to mammals. The sequences of ATF/CREB families were from organisms as follows: Claviceps purpurea CPTF1 (CAD21519), Paracoccidioides brasiliensis PbAtf1 (EEH39756), Histoplasma capsulatum transcriptional factor (EER37184), Neurospora crassa NcAtfA (XP_961431), Aspergillus clavatus AcAtfA (XP_001271133), Aspergillus nidulans transcriptional factor (XP_660515), Aspergillus flavus AfAtfA (XP_001213842), Magnaporthe oryzae MoAtfA (named MoAtf1 in the paper) (XP_362629), Chaetomium globosum transcriptional factor (XP_001219853), Homo sapiens HsATF2 (AAI07699), Cryptococcus neoformans CnAtf2 (XP_569310), Sclerotinia sclerotiorum SsAtfA (XP_001593486), Schizosaccharomyces pombe SpAtf1 (NP_595652), Fusarium graminearum FgAtfA (XP_390318; accession number from NCBI); Schizosaccharomyces octosporus SoAtf1 (SOCG_00021), Candida parapsilosis transcriptional factor (CPAG_01404), Fusarium verticillioides FvAtfA (FVEG_02866), Fusarium oxysporum FoAtfA (FOXG_05265), Puccinia graminis tritici PgAtfA (PGTG_18061), Verticillium dahliae VdAtfA (VDAG_08676), Rhizopus oryzae transcriptional factor (RO3G_11082; accession number from Broad Institute). 
A

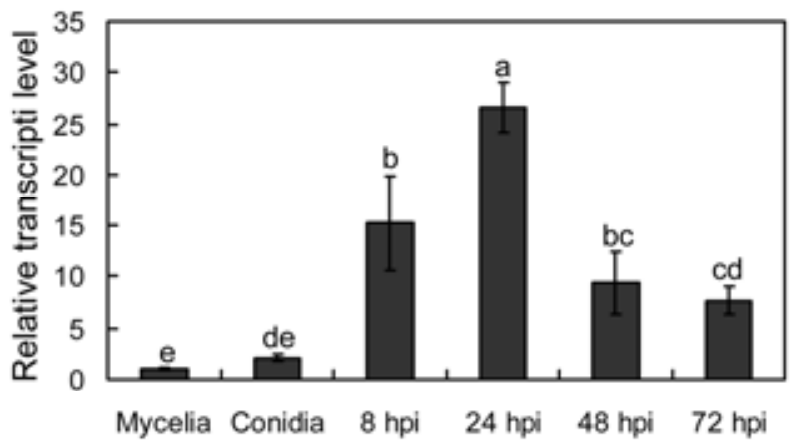

B
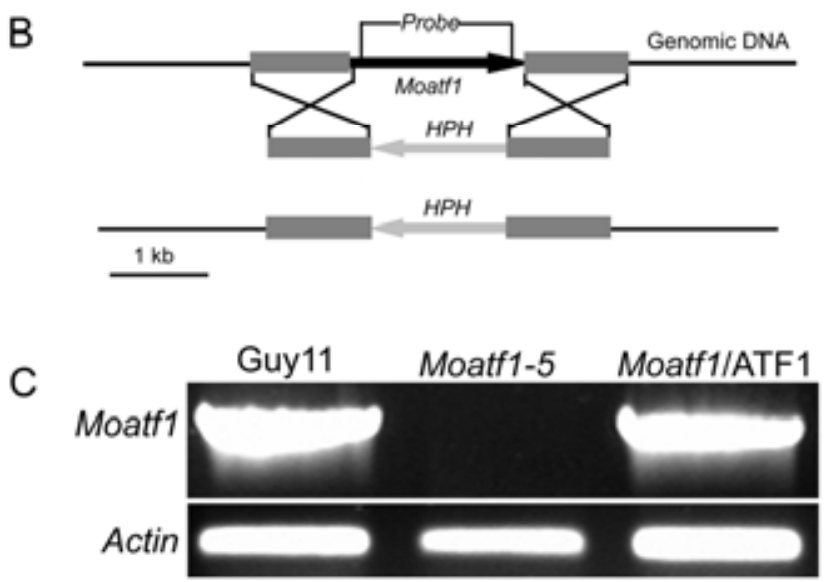

D
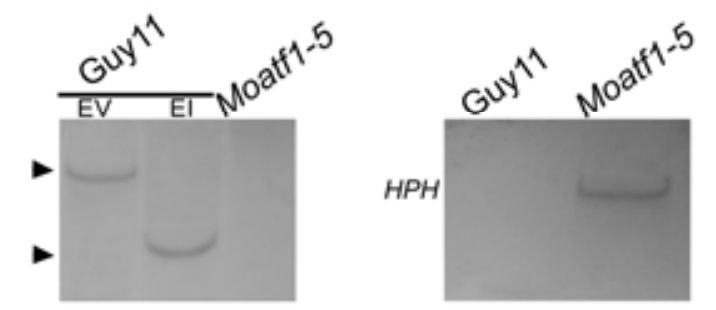

Fig. 2. Phase-specific expression, targeted gene replacement, and complementation of Moatf1 in Magnaporthe oryzae. A, The phase-specific expression of Moatfl was quantified by quantitative real-time polymerase chain reaction (PCR), with the synthesis of cDNA from each sample including infectious growth, vegetative growth, and conidia. Relative abundance of Moatf transcripts during infectious growth (from ungerminated conidia to in planta fungal cells $72 \mathrm{~h}$ postinoculation) was normalized by comparing with vegetative growth in liquid complete media (relative transcript level $=1$ ). Each sample was harvested from 10 plants, and three independent biological experiments with three replicates in each were performed. Representative results from one of these experiments are shown. Significant differences are presented in the figure $(P<0.01)$, and error bars represent standard deviation. B, Moatfl targeted gene replacement strategy. A $1.82-\mathrm{kb}$ fragment of the Moatf1 coding region was replaced with a $1.4-\mathrm{kb}$ fragment containing the hygromycin B-resistance cassette (HPH) to create a Moatfl mutant. The DNA fragment located at the inner space of the Moatf1 deletion region was used as the probe to validate Moatfl deletion transformants by PCR amplification and Southern hybridization. (Scale bar $=1 \mathrm{~kb}$ ). C, Semiquantitative reverse transcription (RT)-PCR was carried out to confirm the deletion and reintroduction of the Moatf1 gene. Complete inactivation of Moatfl transcription in the deletion mutants was verified by RT-PCR, using the cDNA of the wild-type strain, the Moatfl mutants, and the complemented strain. Primer pairs were designed according to the open reading frame of Moatf1. D, Southern hybridization was used to analyze the Moatfl gene copy number and to validate the deletion of the Moatfl gene and the addition of a single copy integration of the $H P H$ gene in the mutant. For confirming the Moatf1 gene copy number in the wild-type genome and the deletion of the Moatf 1 gene in the mutant, both the genomic DNA of Guy11, which was digested with EcoRV (EV) and EcoRI (EI), and the mutant, which was digested with EcoRI, were hybridized with a 1.5-kb Moatfl fragment. The arrowhead in D (left) showed a single band hybridized by the probe in the wild type and no band in the mutant. To validate the single-copy integration of the $H P H$ gene in the mutant genome, the genomic DNA of the Moatf1 mutant was digested with $E c o$ RI and was hybridized with the 1.4-kb $H P H$ fragment. ference was detected in the appressorium turgor (Supplementary Fig. S3). Hence, we transferred our attention to the infectious stage and used the excised leaf sheath assay to examine infectious hyphae within host cells. The infectious hyphae of the wild type grew actively and occupied 5 to 10 cells adjacent to the primary infected cells by 72 hpi (Fig. 4C). However, in the Moatfl mutant, most of the infectious hyphae were blocked in the primary infected leaf-sheath cell (Fig. 4C). The number of infectious hyphae that were confined to initially infected cells was $58 \%$ greater in the Moaft 1 mutant compared with Guy11. In contrast, the number of infectious hyphae in the mutant that invaded more than two cells was $66 \%$ less than that in the wild-type strain (Fig. 4D). Moreover, a large number of the primary infected cells invaded by the Moatfl mutant became dark brown and the infectious hyphae in these cells became swollen (Fig. 4C and E), whereas only a few infected cells invaded by the wild-type strain became dark brown and the infectious hyphae of the wild type grew well in the initially infected cells and easily expanded to neighboring cells (Fig. 4C). These data indicate that the attenuated virulence of the Moatf1 mutant may result from defects in the spread of infectious hyphae.

\section{Intracellular ROS are unaltered in the Moatf1 deletion mutant.}

In Schizosaccharomyces pombe, the transcription factor SpAtf1, together with another parallel transcription factor, Pap1, regulates the genes involved in ROS homeostasis and response to extrinsic oxidative stress (Nguyen et al. 2000; Quinn et al. 2002). For fungi, intracellular ROS have multiple functions in pathogenicity (Egan et al. 2007; Kim et al. 2009; Tanaka et al. 2006). In M. oryzae, the intracellular ROS is crucial for its virulence on rice seedlings and NADPH oxidase deletion mutants lose virulence on the susceptible rice cultivar CO-39 because of obstructed intracellular ROS generation (Egan et al. 2007). Thus, we investigated whether defects in the spread of infectious hyphae of the Moatfl mutant on rice seedlings resulted from disruption of its intracellular ROS homeostasis. The intracellular ROS levels in both the Moatf1 mutant and Guy11 strain were detected, using dihydrorhodamine 123 and nitroblue tetrazolium (NBT) staining, respectively. However, the two staining results showed no significant difference when assessing the intracellular ROS production from conidia to mature appressoria (Fig. 5A and B), indicating that Moatf1 is not associated with the regulation of intracellular ROS generation in $M$. oryzae. And these results also indicated that the attenuated virulence of the Moatfl mutant apparently does not cause any disturbance of intracellular ROS homeostasis.

\section{The Moatf1 deletion mutant shows sensitivity to oxidative stress.}

The stress-tolerance mechanisms of plant pathogens play an important role in virulence (Andersson et al. 1999; Chi et al. 2009; Lin et al. 2009; Molina and Kahmann 2007). We therefore investigated whether the attenuated virulence of the Moatfl mutant resulted from a variation in resistance to osmotic or salt stresses. Under the condition of either $1 \mathrm{M}$ sorbitol or $0.5 \mathrm{M} \mathrm{NaCl}$, mycelial growth rate of the Moatfl mutant did not differ compared with that of Guy11 (data not shown). Similarly, in sodium dodecyl sulfate-containing medium, no evident growth differences were observed between the Moatfl mutant and the wild-type strain Guy11 (Supplementary Fig. S4).

In $M$. oryzae, defects in cell-wall composition can influence appressorium formation and impair successful infection of rice (Jeon et al. 2008; Skamnioti et al. 2007; Xu 2000; Xu et al. 1998). However, no distinguishable differences were observed in growth when a cell wall-degrading enzyme was added to 
the CM medium (Supplementary Fig. S2B and C). Similarly, protoplasts released from enzyme-treated mycelia also showed no evident difference. Moreover, when grown on CM medium containing Calcofluor white (CFW) (200 ppm), mycelial growth of the Moatfl mutant was comparable with the wildtype strain Guy11 (CFW inhibition rates of 21.9 and $18.3 \%$, respectively). In addition, we further used nikkomycin $\mathrm{Z}$, the chitin synthetase inhibitor, to determine whether aberrant chitin synthesis occurred in the Moatfl mutant during conidia germination, but no significant differences were visualized between the Moatfl mutant and the wild-type strain, both having the same phenotypes with swollen germ tubes on a hydrophobic microscope coverslip (data not shown).

However, when inoculated under oxidative conditions, mycelial growth of the Moatfl mutant was more sensitive to 5 $\mathrm{mM} \mathrm{H}_{2} \mathrm{O}_{2}$ than that of Guy11, with $11 \%$ more inhibition rates than the wild type (Fig. 6A). Similarly, conidia of the Moatfl mutant displayed sensitivity to $\mathrm{H}_{2} \mathrm{O}_{2}$. Exposure to $5 \mathrm{mM} \mathrm{H}_{2} \mathrm{O}_{2}$ led to a severely decreased germination rate in the Moatfl deletion mutant, which was $76 \%$ less than that of the wild type (Fig. 6B). Moreover, $88.5 \%$ of conidia from the Moatfl mutant did not germinate even after culture for $12 \mathrm{~h}$, as compared with the wild type under these conditions (Fig. 6B). Based on these results, we presume that the Moatfl gene may not be responsible for cell-wall integrity but for the regulation of oxidative stress tolerance in $M$. oryzae.

\section{Moatf1 deletion induces intense plant defense responses.}

Plant defense responses play important roles during plantmicrobe interactions. The recognition of microbe-associated molecules by plant immune systems causes reinforcements of the cell wall, accumulation of pathogenesis-related (PR) proteins, and rapid generation of ROS in the infected cell (Abramovitch et al. 2003; Bradley et al. 1992; Levine et al. 1994; Tanaka et al. 2003; Torres et al. 2005). In this study, infectious hyphae of the Moatfl mutant in the rice cell were restrained in their growth, and became swollen in primary infected cells. Meanwhile, all the rice cells infected by the swollen hyphae of the Moatfl mutant became dark brown (Figs. 4C and 7A). Chi and associates (2009) reported that the des I deletion mutant displayed a similar phenotype, with brown granule generation in infected rice cells because of enhanced defense responses. Hence, we suspect that enhanced defense response is also triggered in the Moatf1 mutant-infected plant.

Phenolic compounds are well-known to have antimicrobial functions and are comprehensively used by plants to reinforce the cell wall during their antimicrobial defense response. These low-molecular weight phenols, like benzoic acids and other phenylpropanoids, are formed in the initial response to infection (Niemann et al. 1991). Generally, such phenolic compounds that accumulate at the site of infection can be excited by UV light and detected using a fluorescence microscope. For the wild-type strain Guy11, such autofluorescence was barely visible in the cytoplasm of primary infected cells and cells infected by the spread-infection hyphae. In contrast, cells infected by the Moatfl mutant emitted intense autofluorescence, both in infected cells and neighboring uninfected cells (Fig. 7A).

ROS accumulation at the infection site, well-known as an oxidative burst, is regarded as one of the earliest events during incompatible interactions between plants and pathogens (Apostol et al. 1989; Yoshioka et al. 2008). Thus, we examined the host-
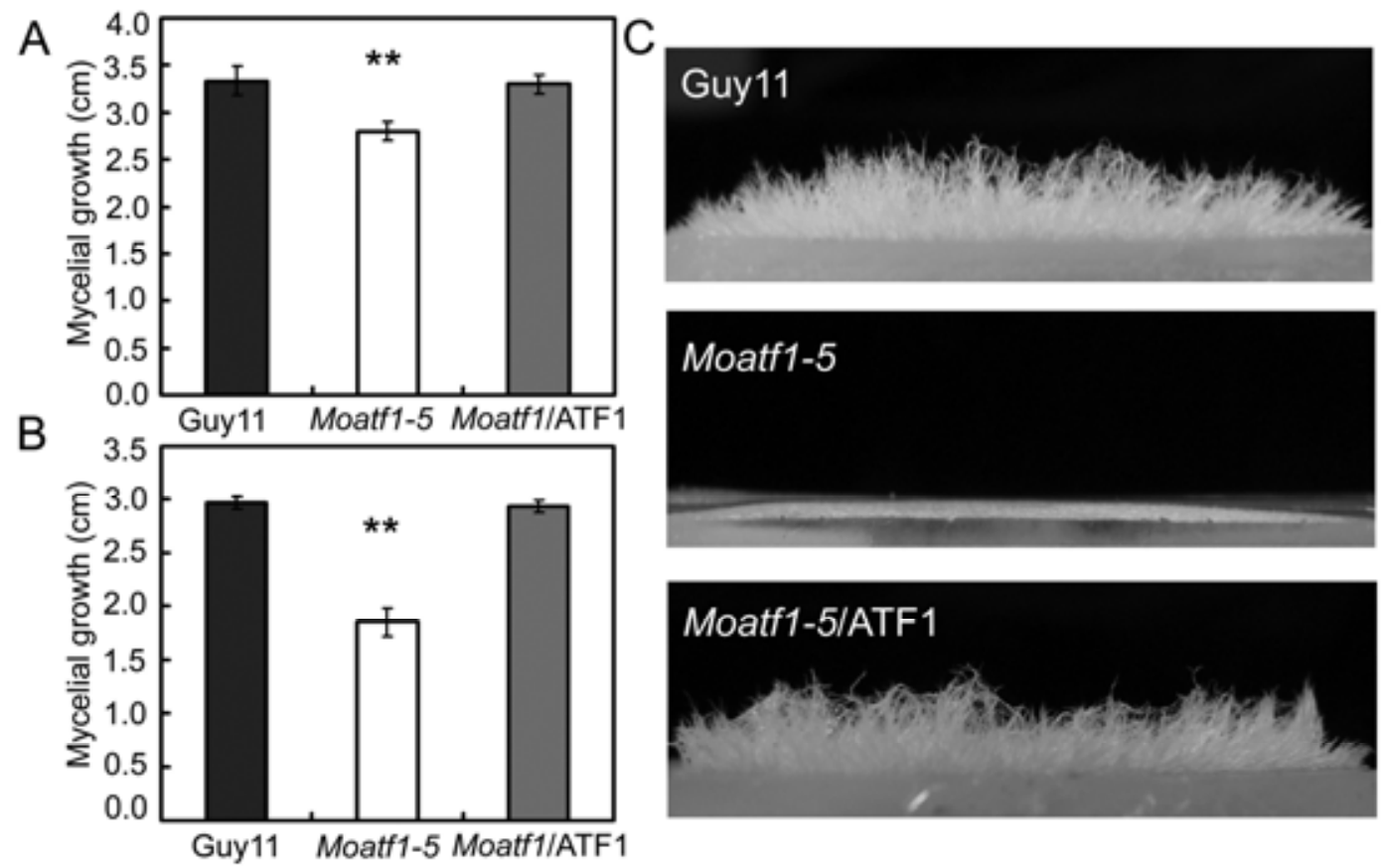

Fig. 3. Growth characteristics of the Moatf1 mutant on two artificial nutrient media. A, Statistical analysis of mycelia growth rate on complete media (CM). Wild type Guy11, Moatf1 mutant, and the complemented strain mutant were inoculated on $\mathrm{CM}$ medium and were cultured at $28^{\circ} \mathrm{C}$ for 5 days. Colony diameters were measured and the average diameters of the wild type, mutant, and complemented strain were used to evaluate significant differences in mycelial growth rates. Three independent biological experiments were performed with three replicates each time and yielded similar results. Representative results are shown. B, Statistical analysis of mycelial growth rate on minimal medium (MM). Wild type, Moatf1 mutant, and the complemented strain mutant were inoculated on $\mathrm{MM}$ and were cultured under at $28^{\circ} \mathrm{C}$ for 4 days. Colony diameters were measured, and the average diameters of wild type, mutant, and complemented strains were used to evaluate significant differences in mycelial growth rates. Three independent biological experiments were performed with three replicates each time and yielded similar results. Representative results from one experiment are shown. C, Aerial hyphae growth reduced in the Moatf1 mutant on CM media. Wild type, Moatf1 mutant, and the complemented strain were inoculated on $\mathrm{CM}$ medium and were cultured at $28^{\circ} \mathrm{C}$ for 5 days. The aerial hyphae growth of each strain was photographed. Three independent biological experiments were performed, and similar results were obtained. The representative results are displayed. Asterisks in A and B represent significant differences among Guy11, Moatf1 mutant, and the complemented strain $(P<0.01)$, and error bars represent the standard deviation. 
derived ROS by staining with 3, 3'-diaminobenzidine (DAB) 48 $\mathrm{h}$ after inoculation. Rice cells with infectious hyphae of the wild-type strain were not stained by $\mathrm{DAB}$, and no reddish brown precipitate was observed in infected cells (Fig. 7B). However, the primary infected rice cells with infectious hyphae of the Moatf1 mutant were intensely stained by DAB, with an enhanced amount of reddish brown precipitate around the appressoria and infected cells, indicating that the Moatfl mutant failed to scavenge the accumulated $\mathrm{H}_{2} \mathrm{O}_{2}$ at the infection site (Fig. 7B).
$\mathrm{H}_{2} \mathrm{O}_{2}$ produced by the NADPH oxidases could act as a diffusible second messenger for defense-gene induction and is essential for the pathogen-associated molecular pattern (PAMP)triggered immunity (PTI) response in plants (Nurnberger et al. 2004). Therefore, to further determine whether plant defense genes are activated by the Moatfl mutant, transcript levels of six defense-related genes involved in jasmonic acid (JA) (Lox, $P B Z 1, A O S 2)$ or salicylic acid (SA) pathways (PRIa, PAD4, $C h t 1)$ were examined using real-time qRT-PCR in plants in-
A Guy11

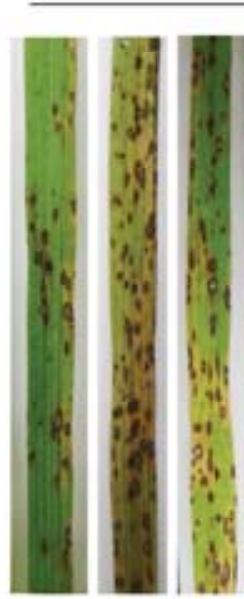

C

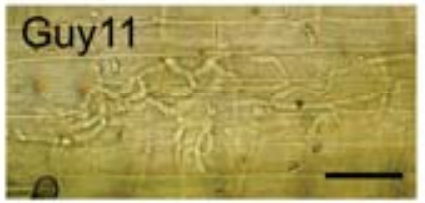

$\mathrm{D}$

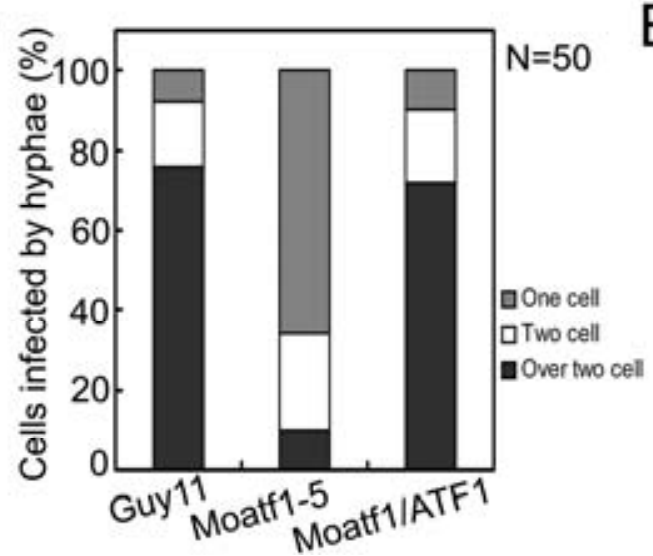

Moatf1-5
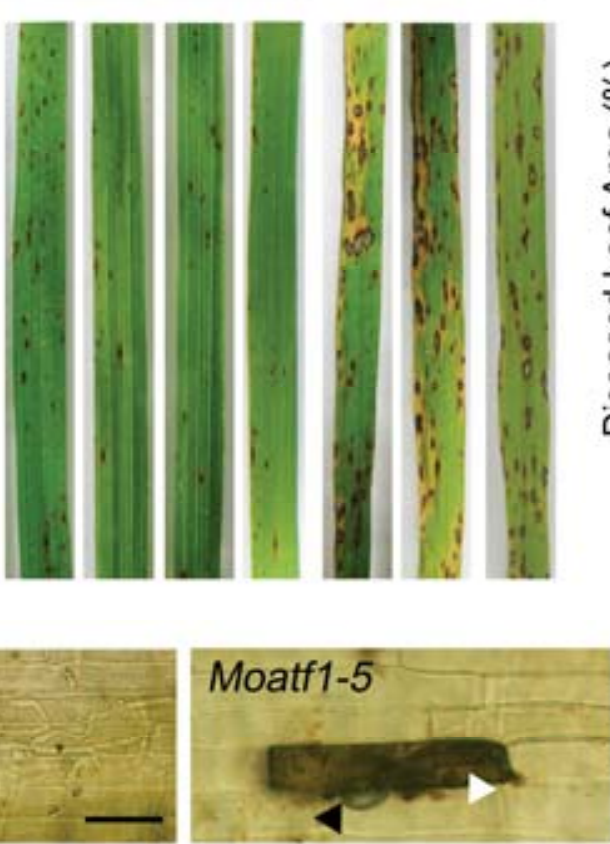
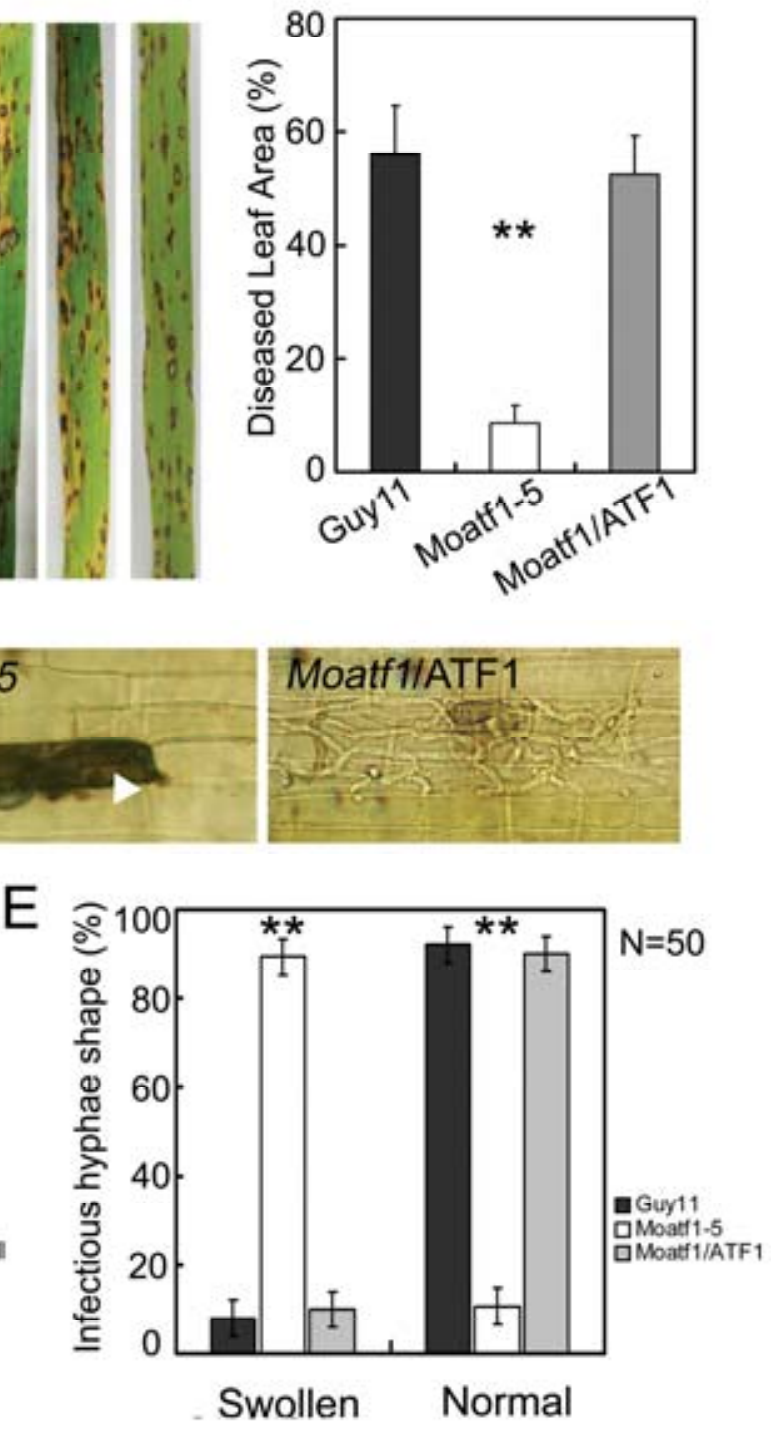

Fig. 4. Pathogenicity of the Moatfl mutant strain. A, Pathogenicity assay. Conidial suspension $\left(4 \mathrm{ml}, 1 \times 10^{5} \mathrm{conidia} / \mathrm{ml}\right)$ of each strain was sprayed on 4 week-old rice seedlings (Oryza sativa cv. CO-39), and 60 healthy rice plants were used in each independent experiment. Diseased leaves were harvested 5 days after inoculation. Three independent experiments were performed and similar results were obtained. The representative photographs are presented. B, Disease severity of each strain was assessed from the percentage of diseased leaf area as described by Fang and Dean (2000). Values are the mean \pm standard deviation from four rice leaves inoculated by each strain. Asterisks represent significant difference $(P<0.01)$ among Guy 11, Moatf1 mutant, and the complemented strain. C, Microscopic observation of penetration and infectious hyphae expansion on rice leaf-sheath cells. Excised rice sheath from 4-week-old rice seedlings $\left(O\right.$. sativa cv. CO-39) was inoculated with conidial suspension $\left(1 \times 10^{4}\right.$ conidia per milliliter of each strain). Infectious hyphae growth was observed $72 \mathrm{~h}$ after inoculation. Dark arrowheads represent appressorium, white arrowheads indicate swollen hyphae. Three independent experiments were performed and similar results were obtained. The representative photographs from one of the independent experiments are presented. $($ Scale bars $=50 \mu \mathrm{m})$. $\mathbf{D}$, Percentage of infected rice cells occupied by infectious hyphae of Guy11, Moatf1 mutant, and Moatf1/ATF1. The total number of appressorium-mediated penetration and infection is indicated (top right corner, $N=50$ ). Infectious growth was observed as described above. Three independent experiments were performed and similar results were obtained. Representative results from one of these experiments are presented. E, Percentage of swollen infectious hyphae in the rice cells by strain Guy11, Moatf1 mutants and Moatf1/ATF1. The total number of appressorium-mediated penetration and infection is indicated (top right corner, $N=50$ ). Infectious growth was observed as described above, and the percentage of swollen infectious hyphae of strains Guy11, Moatf1 mutant, and Moatfl/ATF1 in the rice cells was analyzed. Three independent experiments were performed and similar results were obtained. Representative results from one of these experiments are shown. Asterisks represent significant difference among Guy11, Moatf1 mutant, and complemented strain Moatf1/ATF1. 
fected by the Moatf1 mutant or Guy11. The activation of these genes differed, depending on whether the rice plants were inoculated with the mutant or with the Guy11 strain. Much higher levels of expression of all genes were observed in rice plants infected with the Moaftl strain in comparison with the wild type. In the Moatf1 mutant-infected plants, strong expression of the Cht 1, PAD4, and Lox genes was apparent in rice plants $24 \mathrm{~h}$ after inoculation, declining thereafter (Fig. 8). The expression of the PRla, PBZ1, and AOS2 genes continued to increase during the infection timecourse (Fig. 8). In contrast, these genes were not induced or were expressed at much lower levels in plants infected by the wild-type strain (Fig. 8). Based on the results above, we conclude that poor growth of the Moatfl mutant in rice cells may be, at least in part, due to the strong activation of plant defense responses.

\section{Inhibition of plant ROS generation restores extension of infectious hyphae of the Moatf1 mutant.}

The accumulation of ROS functions as a second signal mediating plant defense (Alvarez et al. 1998; Gechev and Hille 2005; Lamb and Dixon 1997; Li et al. 2006; Nurnberger et al. 2004). The activation of ROS scavenging by phytopathogens is a mechanism to cope with plant defenses and allow infection (Chi et al. 2009; Molina and Kahmann 2007; Nathues et al. 2004). We hypothesized that the blocked hyphal growth in the infected cell and attenuated virulence of the Moatfl mutant on CO-39 were due to a defect in scavenging ROS generated by the host plant. To this end, an excised leaf-sheath assay was performed, using the diphenyleneiodonium (DPI) treatment to inhibit activity of the plant NADPH oxidases, which are considered to be one of the most important generators of ROS (Bolwell et al. 1998; Grant et al. 2000; Torres and Dangl 2005). After incubation at $28^{\circ} \mathrm{C}$ for $72 \mathrm{~h}$, three to four layers of leaf-sheath endodermis cells were observed under a light microscope. Without DPI treatment, the infectious hyphae of the Moatfl mutant in plant cells looked swollen and were restricted to primary infected cells, enclosed by numerous dark brown granules, in contrast to the wild-type strain that actively grew in these rice cells (Fig. 9). When treated with $0.5 \mu \mathrm{M}$ DPI to inhibit the plant-derived ROS generation but not affect germination and growth of the wild type or mutant, the previously blocked infectious hyphae of the Moatfl mutant were rescued and could expand into neighboring cells. Similarly, the virulence of the mutant on leaf-sheath cuticle cells was also restored after treatment with DPI (Fig. 9). Furthermore, infectious hyphae of the mutant were restored to their original shape in the host cells and did not differ from those of the wild type (Fig. 9). This suggests that the scavenging of host-derived ROS at the infection site is essential for the virulence of Moatfl mutant, and the deletion of Moatfl might be the vital reason for the failure of infectious growth.

\section{Moatf1 deletion decreases the activity of extracellular peroxidases and laccases.}

Fungal peroxidases may be detected by use of specific dyes (Cripps et al. 1990; Mileski et al. 1988). Peroxidases can generate free radicals that oxidize dyes and result in discoloring (Cripps et al. 1990). Congo red (CR), one such dye that binds with the cell-wall component $\beta$-1,4-glucans, is often used to detect cell-wall integrity in microorganisms (Chi et al. 2009). It can also be oxidized via peroxidase produced by fungal cultures and, thus, serve extensively as an indicator for the presence of secreted peroxidases. In this study, to determine the cell-wall integrity of the mutant, $\mathrm{CR}$ was added to the $\mathrm{CM}$ medium, but mycelial growth of the Moatf1 mutant on media containing $200 \mu \mathrm{g}$ CR per milliliter was similar to that of the wildtype Guy11 (17.1 vs. $14.5 \%$ inhibition, respectively) (Supplementary Fig. S1C). However, a degradation halo of CR on the Moatfl mutant plates was not apparent, whereas a bright golden degradation halo of $\mathrm{CR}$ was observed on plates of the wildtype strain Guy11 (Fig. 10A). These results suggest a deficiency of CR-degrading activity in the Moatfl mutant strain of $M$. oryzae. An enzyme activity assay using culture filtrates of both the Moatfl mutant and wild-type Guy11 showed that the Moatfl

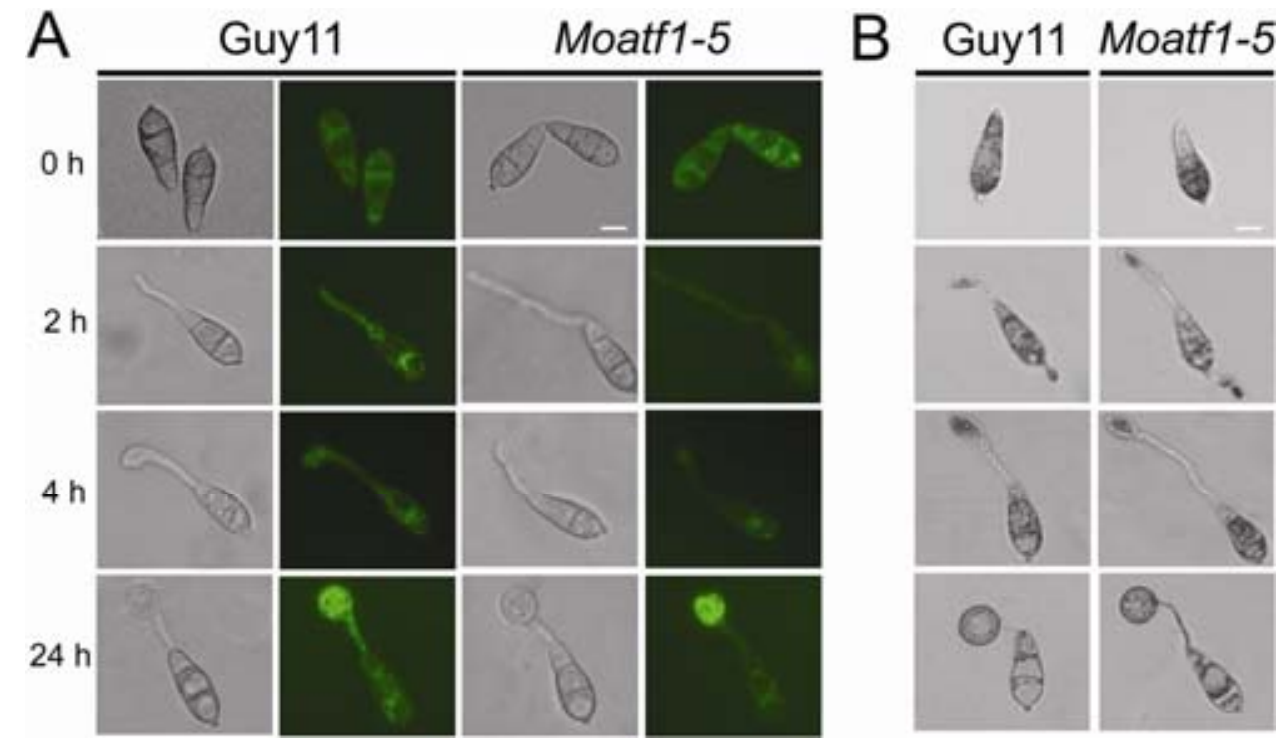

Fig. 5. Reactive oxygen species production during infection-related development of Magnaporthe oryzae. A, Detection of superoxide by dihydrorhodamine 123 staining during conidia germination to appressorium formation in $M$. oryzae Guy11. Conidia were inoculated on a hydrophobic microscope coverslip and were incubated in a moist chamber at $28^{\circ} \mathrm{C}$ for $0,2,4$, and $24 \mathrm{~h}$ before being stained with a $50 \mu \mathrm{M}$ dihydrorhodamine 123 aqueous solution for $2 \mathrm{~h}$, and then, were rinsed twice with phosphate-buffered saline and were viewed by epifluorescence microscopy. Fluorescence images were captured using a 100 -ms exposure for absorbed light using a green fluorescent protein filter. Representative Bright-field images at each timepoint are shown. Three independent experiments were performed and yielded the similar results. Representative results from one of these experiments are presented (Scale bars $=10 \mu \mathrm{m})$. B, Detection of superoxide by nitroblue tetrazolium (NBT) staining during infection-related development in $M$. oryzae. Samples were prepared as for the dihydrorhodamine 123 staining before being stained with a $0.3 \mathrm{mM} \mathrm{NBT}$ aqueous solution for $1 \mathrm{~h}$, and then, viewed by light microscopy at each timepoint. Three independent experiments were performed and yielded the similar results. Representative results from one of these experiments are presented. Scale bars $=10 \mu \mathrm{m}$. 
mutant is virtually deficient in peroxidase activity and showed a very low level of peroxidase activity in the extracellular culture filtrate in comparison with the wild-type strain Guy11 (Fig. 10C). We also determined the activity of another extracellular enzyme, laccase, in the mutant and wild-type strains when grown on solid or liquid CM medium. In each case, the decreased laccase activity was observed in the Moatfl mutant, with a less-oxidized dark purple stain around the colony of the Moatfl mutant and a lower level of laccase activity in the culture filtrate compared with the wild-type strain (Fig. 10B and D). These data suggest that Moatfl deletion resulted in decreased activity of peroxidases and laccases in $M$. oryzae.

\section{Moatf1 deletion affects the expression of several extracellular peroxidases.}

The decreased activity of extracellular peroxidases and laccases observed in the Moatfl mutant may be due to reduced transcription of these enzymes encoding genes. Thus, we examined the expression profiles of several extracellular peroxidase
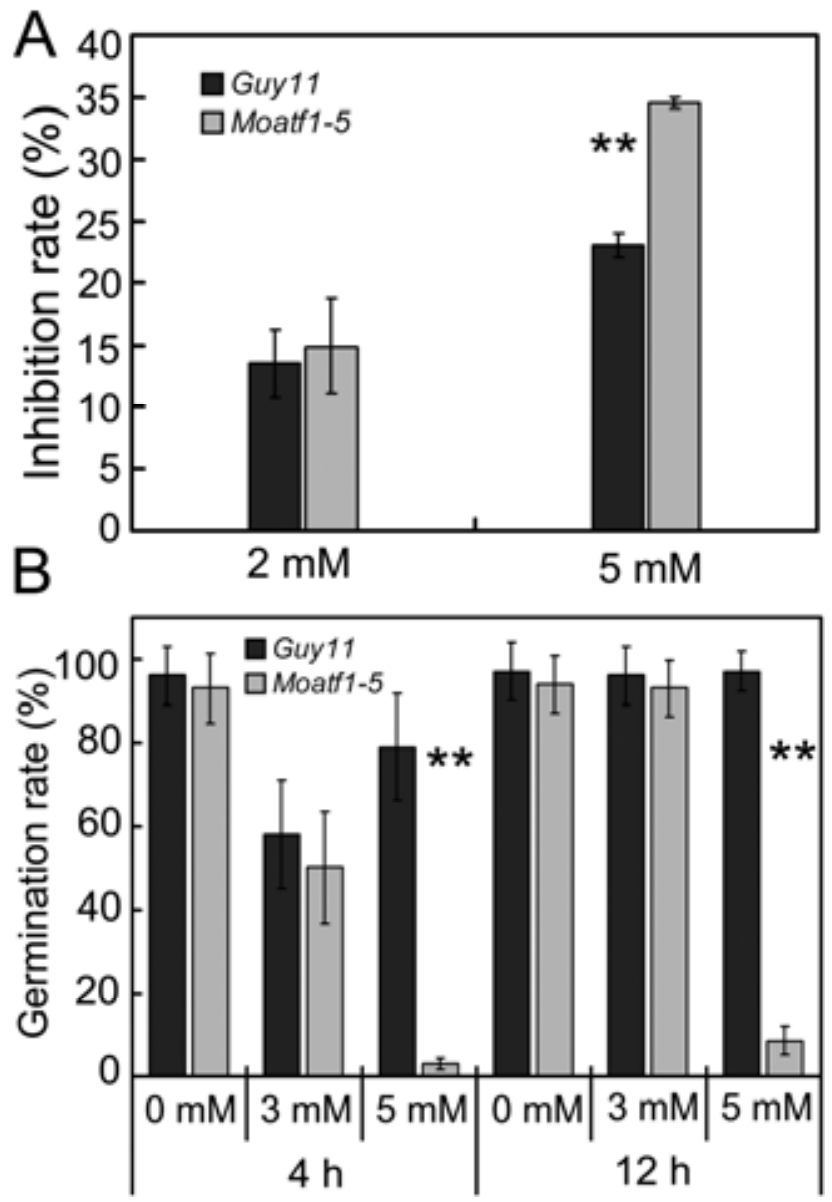

Fig. 6. Hypersensitivity of the Moatf1 mutant to oxidative stress. A, Statistical analysis of mycelial growth of both Moatf1 mutant and Guy11 on complete agar medium under oxidative stress. Colony diameters were measured in each independent biological experiment. Measurements of growth inhibition rate are relative to the growth rate of each untreated control. Three independent biological experiments were performed with three replicates each time, and similar results yielded in each biological experiment. Error bars represent the standard deviation, and asterisks represent significant difference between Guy11 and Moatf1 mutant $(P<0.01)$. B, Conidia germination rates were analyzed after treatment without or with 3 or $5 \mathrm{mM} \mathrm{H}_{2} \mathrm{O}_{2}$. Three independent biological experiments were performed, with three replicates each time and yielded similar results in each independent biological experiment. Error bars represent standard deviation, and asterisks represent significant difference between Guy11 and Moatf1 mutant $(P<0.01)$. and laccase genes in the Moatfl mutant using qRT-PCR. We selected nine genes encoding the putative peroxidases for qRTPCR, according to the annotated $M$. oryzae genome database. All of the selected genes, except for MGG_13239, could be classified into two clades based on a phylogenetic analysis, and the proteins they encoded all possess a signal peptide (Fig. 11). Differences in the expression level of peroxidase genes were observed between the Moatfl mutant and the wild-type strain. In clade 1 , seven peroxidase genes were classified into this group, and four of them showed inducible expression in the wild-type Guy11 under $\mathrm{H}_{2} \mathrm{O}_{2}$ treatment (Fig. 11). In the Moatf1 mutant, all seven genes in clade 1 were reduced in expression in comparison with wild-type Guy11, under normal culture conditions or in response to $\mathrm{H}_{2} \mathrm{O}_{2}$ treatment, and this reduced transcription was not recovered by treatment with $\mathrm{H}_{2} \mathrm{O}_{2}$ (Fig. 11). In clade 2, the expression of peroxidase gene MGG_13239 was oxidative stress-induced and was upregulated in the Moatfl mutant but with a sharp decrease in expression in response to $\mathrm{H}_{2} \mathrm{O}_{2}$ treatment. Another peroxidase gene, MGG_11856, also showed decreased expression in the mutant and is unable to recover under $\mathrm{H}_{2} \mathrm{O}_{2}$ treatment.

To determine laccase expression levels, 11 putative genes encoding laccases were selected from the $M$. oryzae genome database for qRT-PCR. Transcripts of four of the 11 genes were undetectable in the wild-type and the mutant strains of $M$. oryzae under the given conditions and were not further examined. The remaining seven putative laccase genes were tested for transcriptional differences between the wild-type and mutant strains. The results show that six of seven putative laccase genes are significantly reduced in expression in the Moatfl mutant compared with Guy11 (Supplementary Fig. S5).

\section{DISCUSSION}

In this report, we identify a putative bZIP transcription factor in M. oryzae, Moatf1, a homolog of ATF/CREB from yeasts to mammals. The typical leucine zipper structure occurs adjacent to the basic region and, in atf1, contains five leucine residues in the functional bZIP domain (Landschulz et al. 1988). However, our sequence alignment of Moatf1 revealed a missing leucine residue in the leucine zipper region, similar to the structure of a documented transcriptional factor CPTF1 in the phytopathogen $C$. purpurea (Nathues et al. 2004).

In the fission yeast $S$. pombe, two parallel $\mathrm{H}_{2} \mathrm{O}_{2}$-responsive pathways are present. The mitogen-activated protein kinase (MAPK) Sty1 pathway, together with the yap1-like transcription factor Pap1, regulate genes in response to oxidase stress (D'Autreaux and Toledano 2007). Atf1, occurring downstream of MAPK Sty1, is mainly responsible for the regulation of genes involved in response to oxidative stress (Nguyen et al. 2000; Quinn et al. 2002). In S. pombe, mutants lacking atfl are sensitive to different stresses, similar to mutants lacking Sty1 or Wis1 (Degols and Russell 1997; Shiozaki and Russell 1996; Wilkinson et al. 1996). In Aspergillus oryzae, the atfA gene controls conidial germination and stress tolerance, and its deletion mutant is susceptible to oxidative stress (Sakamoto et al. 2009). In the phytopathogen C. purpurea, deletion of CPTF1, a homolog of ATF/CREB, impairs the ability to grow under oxidative-stress conditions and affects virulence on rye (Nathues et al. 2004). Here, our data also indicate that Moatfl deletion leads to increased sensitivity to $\mathrm{H}_{2} \mathrm{O}_{2}$ in both mycelia and conidia of $M$. oryzae. Meanwhile, the Moatfl deletion mutant impairs the ability to lead to pathogenicity on rice, and these results quite agree with the deletion of $C P T F 1$ in the phytopathogen $C$. purpurea.

ROS production is widespread and has many functions in eukaryotic cells, including roles in cellular defense and cell dif- 
ferentiation (Aguirre et al. 2005; Apel and Hirt 2004; Mittler 2002). In plants, the generation of ROS is regarded as one of the first responses to fungal invasion (Mellersh et al. 2002). For plant pathogens and entophytes, ROS also play an important role and the disruption of the intracellular ROS homeostasis can result in functional defects. In the entophytic fungus Epichlö̈ festucae, ROS production by NADPH oxidase is essential for its colonization of plant tissues and the deletion of noxA or its regulatory subunit RacA leads to decreased ROS production and destroys the fungus-plant mutualistic symbioses (Tanaka et al. 2006, 2008). Similarly, In M. oryzae, evidence exists that intracellular ROS levels are crucial for its virulence on rice and that depression of ROS in infectious structures of a mutant strain is proposed to be the main reason for the loss of pathogenicity (Egan et al. 2007). However, in Alternaria brassicicola, the deletion of tmpL leads to hypersensitivity to oxidative stresses and excess oxidative burst in fungal cells during conidiation and plant penetration and, ultimately, impaired virulence on green cabbage (Kim et al. 2009). Based on the results above, it seems that ROS homeostasis in phytopathogens is quite essential for its virulence on host plants. However, comparison of ROS generation between the Moatfl mutant and the wild-type strain showed no differences. Therefore, we deduce that the decreased virulence of the Moatfl mutant cannot be ascribed to disturbing ROS homeostasis in the pathogen.

Induced immunity in plants to pathogenic microbes occurs through two pathways. One is based on PTI, and the other is based on effector-triggered immunity (Chisholm et al. 2006; Jones and Dangl 2006). PTI, regarded as the plant's first active response to microbial perception, can induce plant defensegene expression (Nurnberger et al. 2004). Lox is an important enzyme that participates in the biosynthesis of JA, a signaling molecule in induced disease resistance of rice (Mei et al. 2006; Qiu et al. 2007). In Moatf1 mutant-infected plants, the transcription of Lox is hyperactivated, as compared with rice plants infected by the wild-type strain Guy11. Meanwhile, the SA-dependent pathway component corresponding to the PR gene Chtl also displayed a transcriptional pattern similar to Lox. In addition, PR1a, PBZ1, and AOS2, key components in the JA or SA pathways and involved in JA- and SA-induced plant defense (Mei et al. 2006; Qiu et al. 2007), also showed a stronger activation in mutant-inoculated plants compared with controls. In view of the accumulation of phenolic compounds in plant cells infected with the Moatfl mutant, we examined the transcription of selected genes involved in the phenylpropanoid biosynthetic pathway. In comparison with plants infected with the wild-type Guy11, each gene displayed enhanced transcription in plants infected by the Moatfl mutant $24 \mathrm{~h}$ after inoculation, and these results quite agree with the autofluorescence observed on the rice leaf sheath.

In plants, accumulation of ROS at the site of infection is considered to be one of the earliest responses during plant PTI (Apostol et al. 1989; Nurnberger et al. 2004). Plant-derived ROS plays a variety of functions during plant-microbe interactions (Abramovitch et al. 2003; Bradley et al. 1992; Levine et al. 1994; Lin et al. 2009; Tanaka et al. 2006; Torres et al. 2005). For pathogens to survive in harsh environments and successfully invade host cells, they have to develop mechanisms to scavenge ROS and protect against ROS-induced damage (Apel and Hirt 2004; Miller and Britigan 1997; Moye-Rowley 2003; Toone and Jones 1999). The necrotrophic fungus $S$. sclerotiorum produces oxalic acid, which effectively suppresses host plantgenerated ROS to facilitate penetration and colonization (Cessna et al. 2000). In addition, several peroxidase genes, controlled by yap 1 from $U$. maydis and des 1 from $M$. oryzae, are likely responsible for ROS detoxification at the infection site, and deletion mutants of these genes affect virulence on host plants (Chi et al. 2009; Molina and Kahmann 2007).

In this study, we found that the Moatfl mutant had no apparent defects in appressorium formation or penetration but had retarded infectious hyphae growth and reduced virulence on the susceptible rice cultivar CO-39. In view of the sensitivity of the mutant strain to $\mathrm{H}_{2} \mathrm{O}_{2}$, we suspected that such a result may due to the lost or severely weakened $\mathrm{H}_{2} \mathrm{O}_{2}$-degrading ability in the mutants. This hypothesis was substantiated by further experiments. The DAB staining assay indicated that greater amounts of $\mathrm{H}_{2} \mathrm{O}_{2}$ accumulated in rice cells around the appressorium and initially infected cells when inoculated with the Moatfl mutant compared with the wild-type strain. It is well-known that $\mathrm{H}_{2} \mathrm{O}_{2}$, acting as a second messenger for defense-gene induction, is essential for the PTI response in plants (Nurnberger et al. 2004). Thus, linked with the results of the enhanced expression of the JA or SA marker gene in the Moatfl mutant-infected plants; it is assumed that the accumulated $\mathrm{H}_{2} \mathrm{O}_{2}$ not scavenged by the mutant may be responsible for PR-gene induction in the mutantinfected plants. When DPI, an inhibitor of NADPH oxidases that suppress plant ROS production (Morre 2002), was applied to restrain the host-derived ROS, development of the infectious hy-

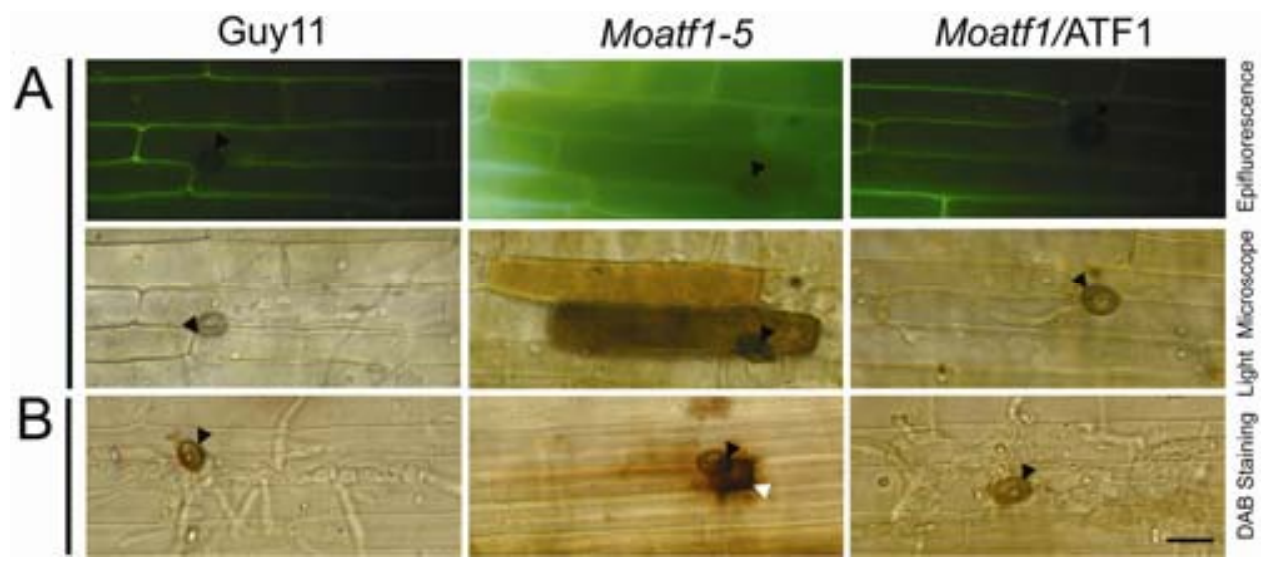

Fig. 7. The Moatf1 deletion mutant induced strong plant defense responses. A, Both fluorescence and light microscopy were performed on infected rice sheaths (Oryza sativa cv. CO-39) 24 h after inoculation. Fluorescence images were captured using a 230-ms exposure for absorbed light, using a green fluorescent protein filter, and light images were captured using a 430-ms exposure of general white light. Dark arrowheads indicate appressorium. Three independent experiments were performed and yielded similar results. Representative results from one of these experiments are presented. Scale bars $=30 \mu \mathrm{m}$. B, 3, 3'-Diaminobenzidine staining of the excised leaf sheath of rice infected by Moatfl mutant and Guy11, 48 h after inoculation. Dark arrowheads indicate appressorium and the white arrowhead indicates dark brown precipitate. Three independent biological experiments were performed and yielded similar results. Representative results from one of these experiments are presented. Scale bars $=30 \mu \mathrm{m}$. 
phae of Moatf1 mutant recovered in rice cells and was similar to that of the wild-type strain. Such result further suggested that host-derived ROS may play an important role in the Moatfl mutant infection and its inhibition may result in a dramatic reduction of the plant defense response on rice and, thus, may allow the mutant infection. Combined with hypersensitivity to $\mathrm{H}_{2} \mathrm{O}_{2}$ in vitro, we hypothesized that the transcription factor Moatf1 in $M$. oryzae may be responsible for the scavenging of host-derived ROS and that this function may be essential for the inhibition of plant defense response and the spread of infection hyphae in plant tissues.

In fungi, the secreted peroxidases are regarded as an important component to help pathogens detoxify host-derived ROS during plant-microbe interactions (Chi et al. 2009; Molina and
Kahmann 2007). In U. maydis, deletion of the yap1 homolog transcription factor affects the expression of two peroxidase genes and results in a reduced ability to scavenge host-derived ROS and an attenuation of virulence (Molina and Kahmann 2007). Similarly, in M. oryzae, the des 1 deletion mutant displays decreased expression of peroxidase genes, and this severely affects the virulence on susceptible rice cultivar Nakdongbyeo (Chi et al. 2009). In the Moatfl mutant, we detected a deficiency of secreted peroxidase activity by measuring $\mathrm{CR}$ discoloration and by directly assaying for peroxidase in culture filtrates. The analysis of expression profiles by qRT-PCR of several secreted peroxidase genes showed that many were reduced in expression in the Moatfl mutant. Furthermore, the activity of laccase, which is involved in pathogenicity in some fungi (Bar-Nunn et
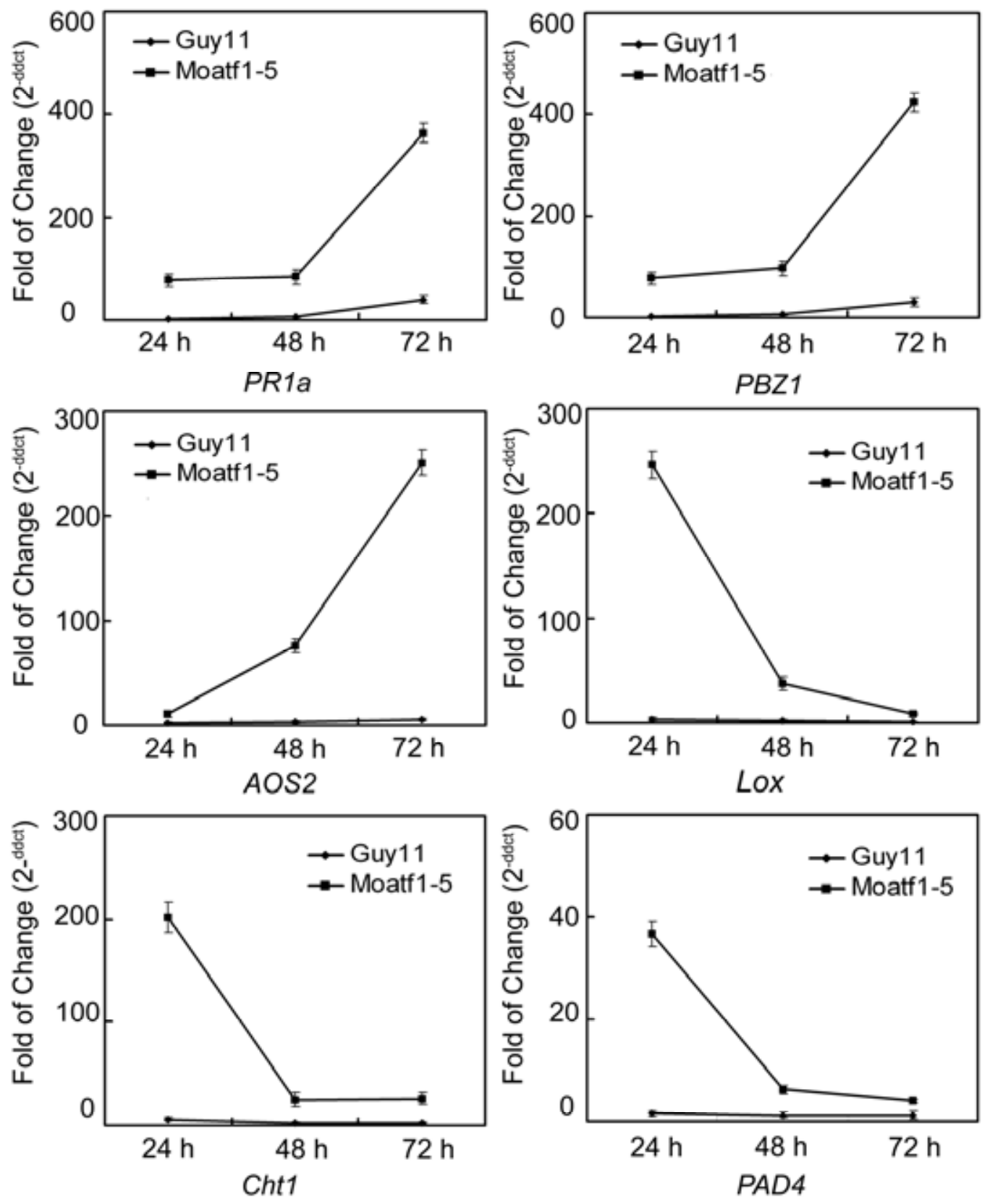

Fig. 8. Expression analysis of defense-responsive genes by quantitative real-time polymerase chain reaction (qRT-PCR) in Moatf1 mutant-infected plants. The transcription of PRla, PBZ1, AOS2, PAD4, Cht1, and Lox in the infected rice was assayed using qRT-PCR. RNA samples were collected from rice plants (Oryza sativa cv. CO-39) 0, 24, 48, and 72 h after inoculation with the Moatf1 mutant or wild-type strain. Each sample was harvested from 10 plants. The average threshold cycle of triplicate reactions was normalized by the stable-expressions gene elongation factor 1a (Os03g08020) in $O$. sativa. Three independent biological experiments were performed and yielded similar results. The representative results from one of these experiments are presented. Error bars in the figure represent the standard deviation. 

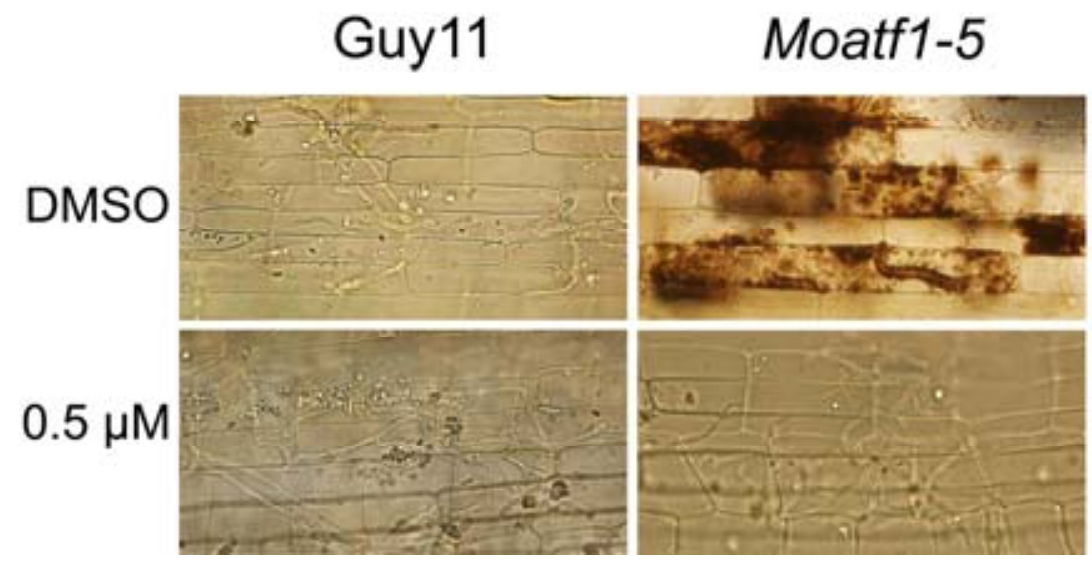

\section{Moatf1/ATF1}

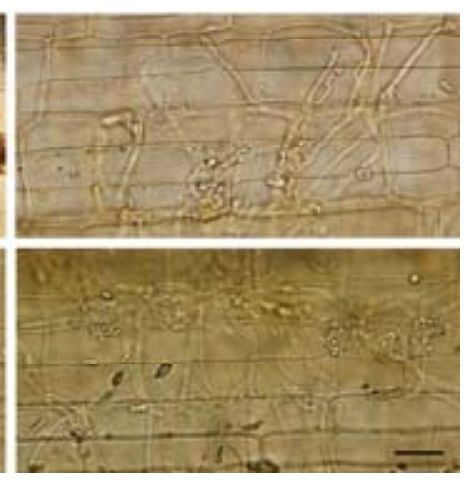

Fig. 9. Infectious hyphae restored by DPI treatment. The excised sheath of rice (Oryza sativa cv. CO-39) was inoculated with conidial suspension $\left(1 \times 10^{4}\right.$ conidia/ml) of Guy11, Moatf1 or Moatf1/ATF1 mutant after treated with or without Diphenyleneiodonium (0.5 $\mu$ M DPI) dissolved in DMSO by three independent experiments. Samples were harvested and observed $72 \mathrm{~h}$ after inoculation. This experiment was performed with three independent biological experiments and representative results from one of these experiments are presented (Scale bar $=30 \mu \mathrm{m})$.
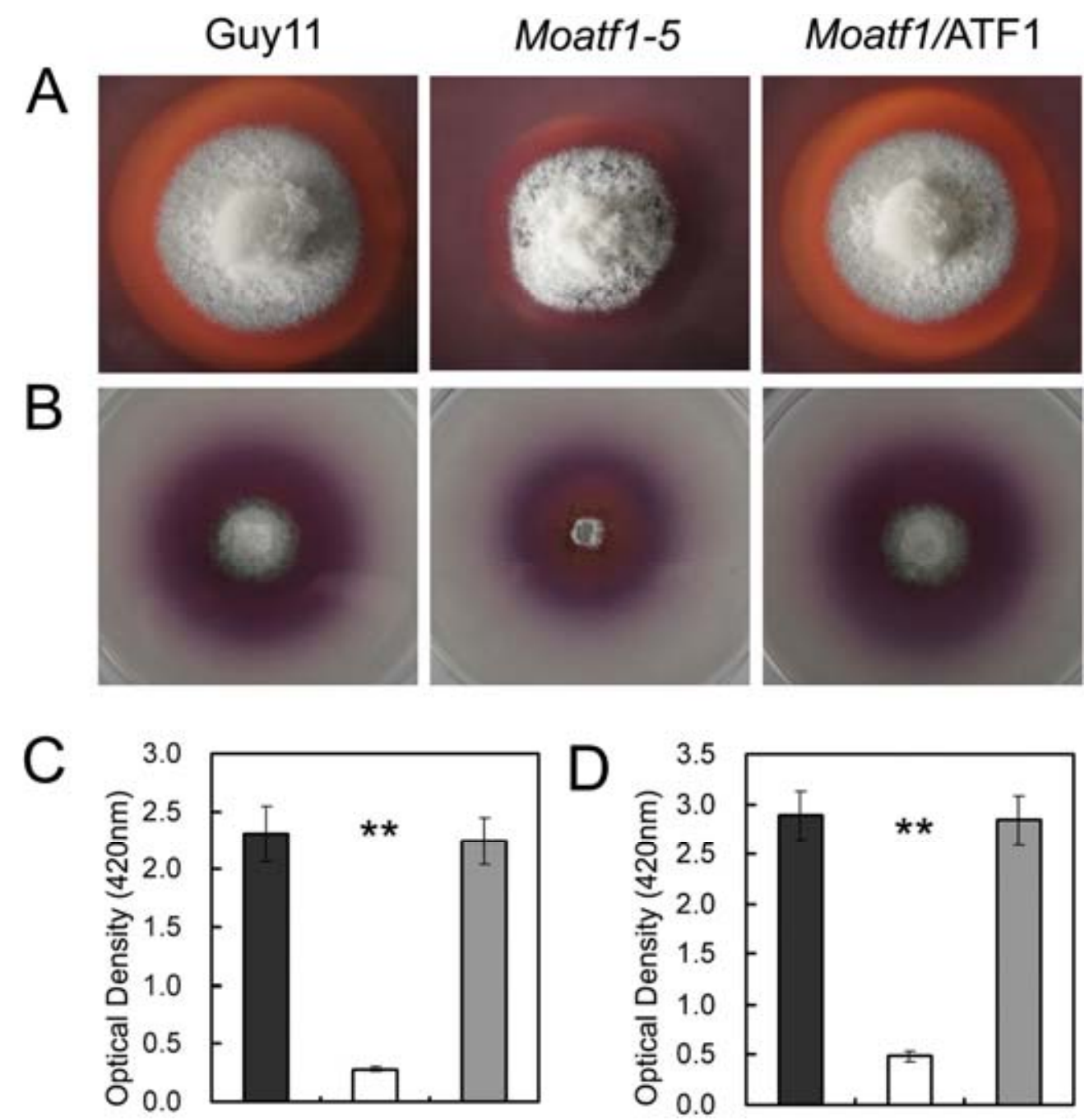

Fig. 10. Compromised activity of extracellular peroxidase and laccase in Moatf1 mutant. A, Laccase activity was monitored in complete media supplemented with $0.2 \mathrm{mM} \mathrm{2,2}$ '-azino-di-3-ethylbenzathiazoline-6-sulfonate (ABTS), 3 days after inoculation. Three independent experiments with three replicates each time were performed and obtained the similar results. Representative results from one of these experiments are shown. B, Guy11 and Moatf1 mutant strains were inoculated on complete media (CM) agar medium containing $200 \mathrm{ppm}$ Congo red (CR) dye at final concentration. The discoloration of CR was observed after inoculation for 5 days. Three independent experiments were carried out with three replicates each time, and similar results were obtained. Representative results from one of these experiments are shown. $\mathbf{C}$ and $\mathbf{D}$, Guy11 and Moatf1 mutant strains were inoculated in CM liquid medium and peroxidase activity (C) and laccase activity (D) were measured in filtrate culture by ABTS oxidization tests with or without $\mathrm{H}_{2} \mathrm{O}_{2}($ Chi et al. 2009). The dark gray columns indicate Guy11, white columns indicate Moatf1 mutant, and light gray columns indicate complement transformant MoatflATF1. Three independent biological experiments with three replicates each were carried out and similar results were obtained. Error bars represent the standard deviation and asterisks in $\mathrm{C}$ and $\mathrm{D}$ represent significant difference among strains tested. 
al. 1988), was monitored in the Moatfl mutant and was determined to be severely reduced in comparison with the wild-type strain Guy11. Likewise, transcription of laccase genes was reduced in the mutant in comparison with the wild type.

Taken together, the results substantiate our hypothesis that the Moatfl deletion affects the transcription of extracellular peroxidases and laccases. This may impair the ability of $M$. oryzae to detoxify host-derived ROS and attenuate the virulence of this pathogen. In conclusion, we identified and characterized an ATF/CREB homolog, Moatf1, in M. oryzae, and our results suggested that this transcription factor plays a key role in mediating oxidative stress responses and scavenging hostderived ROS and is necessary for full virulence of M. oryzae.

\section{MATERIALS AND METHODS}

\section{Fungal strains and growth conditions.}

M. oryzae Guy11 was used as the wild-type strain throughout this work; Both the wild-type strain and its derivative mu- tant were cultured on CM or MM with or without adding different chemicals for 3 to 15 days at $28^{\circ} \mathrm{C}$, to assess the growth and colony characteristics. For conidia collection, strains were normally maintained on corn medium (SDC) (Zhang et al. 2009) at $28^{\circ} \mathrm{C}$ for 10 days and were then transferred to a constant fluorescent light condition to promote conidiation for another 3 to 5 days. Fungal mycelia were harvested from liquid $\mathrm{CM}$ and were used for genomic DNA and total RNA extractions. To observe the vegetative growth under oxidative stress conditions, the proper volume of $\mathrm{H}_{2} \mathrm{O}_{2}$ solution $(3 \%$ [wt/vol]; Aldrich, St. Quentin, France) was applied in solid CM, and the diameters of both the mutant and wild type were measured after 4 days. As for the osmotic stress conditions, it was measured by $\mathrm{CM}$ agar media amended with $0.5 \mathrm{M} \mathrm{NaCl}$ or $1 \mathrm{M}$ sorbitol in final concentration. The cell-wall integrity assay was performed by supplementation of CR (Aldrich) and CFW (Sigma-Aldrich, St. Louis), which is known to inhibit fungal cell-wall assembly by binding chitin and $\beta$-1,4-glucans, respectively (Ram et al. 1994; Wood and Fulcher 1983), with

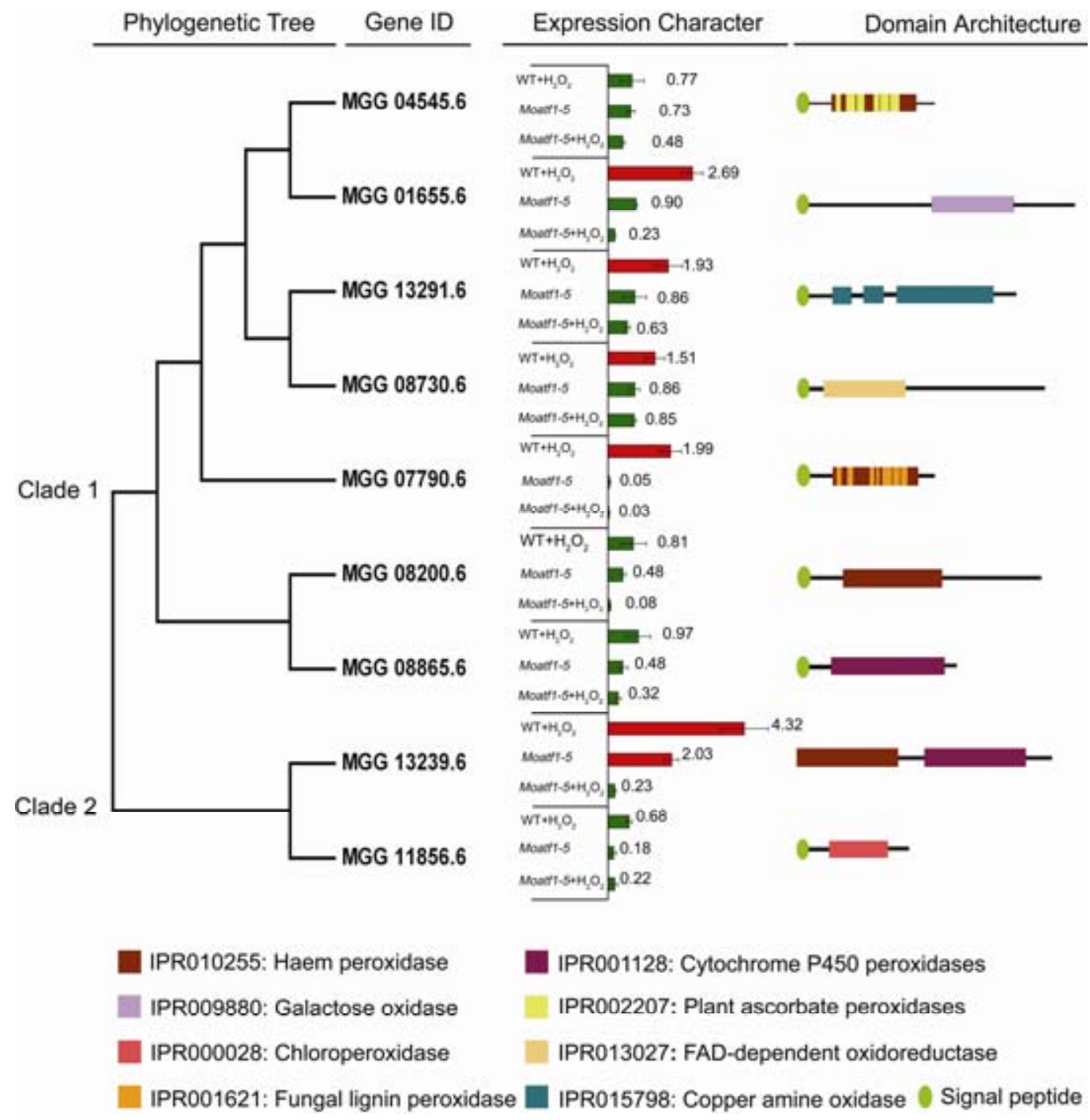

Fig. 11. Extracellular peroxidases expression levels altered in the Moatfl mutant. The nine putative peroxidases displayed were divided into two clades by the Mega3.0 Beta program, with 500 bootstraps. The expression profiles of nine putative peroxidases in the Magnaporthe oryzae genome were checked under normal or oxidative stress-induced condition in both the mutant and the wild-type strain Guy11. Relative abundance of transcript was compared with standard condition (wild-type, normal condition), and the relative transcript levels are indicated in expression character. The average threshold cycle of triplicate reactions was normalized by the stable-expression gene actin (MGG_03982.5) in M. oryzae. Fold changes in the wild-type Guy11 under standard conditions (1.0) are not shown. Three independent biological experiments were carried out with three replicates each time. Representative results from one of these experiments are presented. In the expression character column, the green bars indicates genes downregulated, while the red bars indicates genes upregulated in the strain tested. Domain architecture of nine putative peroxidases was predicted by European Bioinformatics Institute. The InterPro terms and signal peptides of each protein are indicated in the figure. 
final concentration of $200 \mathrm{ppm}$ in CM agar media for 5 days. Sodium dodecyl sulfate was used to analyze cell-wall integrity, by addition in $\mathrm{CM}$ to a final concentration of 0.01 or $0.02 \%$ (vol/wt) for 5 days. To determine the cell-wall integrity during conidia germination, both the conidia of mutant and wild type were incubated on a hydrophobic microscope coverslip (Marienfeld, Landa-Königshofen, Germany) with $100 \mathrm{mM}$ of nikkomycin $\mathrm{Z}$, and germ tubes were observed after $4 \mathrm{~h}$. All the experiments in this section were performed in three independent biological experiments with three replicates in each test.

\section{Targeted gene deletion and complementation of Moatf1.}

For constructing the Moatfl gene replacement construct, a $1.07-\mathrm{kb}$ upstream flanking sequence fragment and a $1.04-\mathrm{kb}$ downstream flanking sequence were amplified from $M$. oryzae genomic DNA by PCR, using the primer pairs FL3115 and FL 4668 and FL4669 and FL3118, respectively (Supplementary Table S1). The two flanking sequences were joined together by overlap PCR with the primer pair FL3115 and FL3118, and the approximately 2-kb amplified segments were purified and cloned into a pMD19-T simple vector (Takara Co., Dalian, China) to generate plasmid pMD-Moatf1. The hygromycin-resistance gene cassette, which encodes hygromycin phosphotransferase under the control of the A. nidulans TrpC promoter (Carroll et al. 1994) was prepared by PCR, using Pfu Taq DNA polymerase (TaKaRa Co.) from plasmid pCB1003 with primer pair FL1111 and FL1112, and was inserted in plasmid pMDMoatfl at the EcoRV enzyme site on the approximately $2-\mathrm{kb}$ fragments to generate the final deletion construct pMD-Moatf1HPH. The 3.5-kb fragment was amplified with the FL3115 and FL3118 primers and wasb transformed into the Guy11 protoplasts. The protoplast-mediated transformation of $M$. oryzae Guy11 was carried out as described by Talbot and associates (1993). Hygromycin B-resistant transformants were selected on solid CM agar media supplemented with 300 ppm hygromycin B. To identify the gene-deleted mutants, all hygromycin B-resistant transformants were screened by using the validated primers FL3119 (F) and FL3120 (R). The mutants were further verified by Southern hybridization to ensure the Moatfl gene deletion. To generate the complementation of the Moatfl mutant, the fragment of the ORF sequence of Moatfl was amplified and inserted into plasmid pCB1532 under control of the TrpC promoter, according to Zhang and associates (2009).

In this report, we have obtained three knockout mutants according to the above methods. And a series of phenotype analyses were conducted on these mutants to functionally characterize the Moatfl gene.

\section{Nucleic acid manipulation and Southern blotting.}

DNA extraction was performed as described by Talbot and associates (1993). Gel electrophoresis, restriction enzyme digestions, ligations, and DNA gel-blot hybridization were performed using standard procedures (Sambrook et al. 1989). For Southern hybridization analysis of the copy number of Moatf1, both $E c o$ RI and EcoRV were used to digest the genomic DNA of wild-type strain Guy11. The digest products were separated on $0.8 \%$ agar gel and were hybridized with Moatf1 probes, which were designed according to its deletion fragments and were amplified from genomic DNA, using primers FL3119 (F) and FL3120 (R). To confirm Moatf1 replacement, labeled Moatf1 probes were used to hybridize the EcoRI-digested genomic DNA from the Moatf1 mutant and wild-type strain Guy11. The copy number of HPH in the Moatfl mutant was detected as described above, using labeled $H P H$ fragments that amplified from the plasmid of pCB1003 with primer pairs FL1111 and FL1112. The whole hybridization was carried out according to the manufacturer's instructions for digoxigenin high-prime
DNA labeling and Detection starter kit 1 (Roche Applied Science, Penzberg, Germany).

\section{RT-PCR and real-time PCR analysis.}

In order to validate the transcripts of Moatf1 in the hygromycin-resistance transformants, total RNA samples were isolated from mycelia cultured for 2 days in liquid CM, using the RNA extraction kit NucleoSpin RNAII (Macherey-Nagel, Bethlehem, PA, U.S.A.). The crude RNA was pretreated with DNase I (TaKaRa) and was then reverse transcribed, using the synthesis system of M-MLV reverse transcriptase (Invitrogen, Carlsbad, CA, U.S.A.). Semiquantitative RT-PCR was carried out to confirm the deletion and reintroduction of the Moatfl gene with the primer pair FL4970 (F) and FL4971(R). The stable-expression actin gene (MGG_03982.5) amplified by primer pairs FL474 (F) and FL475(R) was used as internal control. To examine the Moatf1 mRNA abundance in diverse fungal developmental stages, the total RNA samples were extracted from mycelia grown in liquid CM, and conidia and plants were inoculated with the conidia of Guy11 $\left(1 \times 10^{8}\right.$ spores $\left.\mathrm{ml}^{-1}\right)$ for $8,24,48$, and $72 \mathrm{~h}$, as described above. For detection of the PR gene transcription during infection stage, total RNA samples were extracted from plants inoculated with the wild-type strain or mutant for $0,24,48$, and $72 \mathrm{~h}$ by the method described above. To check the expression of putative peroxidases in the Moatfl mutant under oxidative condition, RNA samples were extracted from 2-day-old mycelia in liquid $\mathrm{CM}$ treated with or without $2 \mathrm{mM}$ of $\mathrm{H}_{2} \mathrm{O}_{2}$ for $1 \mathrm{~h}$. qRT-PCR was used to validate the transcriptional variation of the Moatfl gene during developmental stages, PR genes during the infection course, and peroxidase genes between the wild type and Moatfl mutant. It was performed on the ABI 7300 real-time PCR system (Applied Biosystems, Foster City, CA, U.S.A.) according to the manufacturer's instructions. A $20-\mu \mathrm{l}$ reaction volume contained $2 \mu \mathrm{l}$ of reverse transcription product, $10 \mu \mathrm{l}$ of SYBR premix Ex Taq $(2 \times), 0.4 \mu$ of ROX reference dye $(50 \times$, SYBR PrimeScript RT-PCR kit; TaKaRa), and $0.4 \mu \mathrm{l}$ of each primer $(10 \mu \mathrm{M})$. To compare relative abundance of transcripts of target genes, the average $\mathrm{Ct}$ of triplicate reactions was normalized by the stable-expression actin gene (MGG_03982.5) in $M$. oryzae with primers FL4362 and FL4363 or elongation factor 1a gene (Os03g08020) in O. sativa with primers FL5299 and FL5300. All experiments in this section were performed in three independent biological experiments with three replicates in each test.

\section{Developmental phenotypes observation.}

To investigate the radial colony growth rate, both wild type and the Moatfl mutant were inoculated on CM for 5 days or MM for 4 days with triplicate experiments. Conidia were harvested from 14-day-old colonies grown on SDC in $5 \mathrm{ml}$ of distilled water by scraping. The conidia morphology was observed under a light microscope. Conidia germination and appressoria formation were measured on hydrophobic microscope coverslip (Marienfeld, Landa-Königshofen, Germany). The harvested conidia were filtered through three layers of lens paper and were resuspended to a concentration of $1 \times 10^{4}$ spores per milliliter in sterile water. Drops of conidial suspension $(30 \mu \mathrm{l})$ were placed on the coverslips, with three replicates, and were then placed in a humid condition at $28^{\circ} \mathrm{C}$, and the samples were microscopically observed at intervals. After incubation for $24 \mathrm{~h}$, the percentage of conidial germination and appressorium formation was determined by microscopic examination of at least 100 conidia per replicate in at least three independent experiments. Appressorium turgor was measured as described by Zhang and associates (2009), with three replicates and at least 100 appressoria observed in each replicate. Cell integrity 
was tested on solid medium supplemented with $400 \mathrm{ppm}$ Lysing enzyme (Sigma-Aldrich) in CM medium and cultured for 5 days. Protoplast releasing assays were performed as previously described by Skamnioti and associates (Skamnioti et al. 2007), with a few emendations. Mycelia (2 days old, $1.0 \mathrm{~g}$ ) from liquid CM culture were used to test cell integrity by adding $7.5 \mathrm{mg}$ of Lysing enzyme per milliliter (Sigma-Aldrich) and were counted at every $30 \mathrm{~min}$. All experiments in this section were performed in three independent biological experiments with three replicates in each test.

\section{ROS and superoxide detection.}

Intracellular ROS levels of $M$. oryzae were monitored during the infection-related structure formation, using the oxidantsensitive probe dihydrorhodamine-123 (Invitrogen) and NBT. For dihydrorhodamine-123 staining, drops of conidial suspension $(30 \mu \mathrm{l})$ were placed on the coverslips and were cultured for 0 to $24 \mathrm{~h}$. At each interval, the water surrounding the conidia was carefully removed and replaced with a final concentration of $50 \mu \mathrm{M}$ dihydrorhodamine- 123 at $28^{\circ} \mathrm{C}$ for $120 \mathrm{~min}$, and the conidia were then rinsed twice with phosphate-buffered saline and were viewed by epifluorescence microscopy (Leica Microsystems, Wetzlar, Germany). NBT staining was performed according to Chen and associates (2008). Superoxide production during infection-related structure formation was viewed by Leica DMR bright-field microscope (Leica Microsystems). Both dihydrorhodamine-123 and NBT staining were performed in three independent biological experiments, with three replicates in each test.

\section{Pathogenicity assay and infectious growth observation.}

Conidia used for pathogenicity assays were prepared from 14-day-old cultures and were diluted to the concentration of 1 $\times 10^{5}$ spores per milliliter in sterile water supplemented with $0.2 \%$ (wt/vol) gelatin. Plant infection assays were performed on 4-week-old susceptible rice seedlings (O. sativa) CO-39 by spraying $4 \mathrm{ml}$ of the conidial suspensions with the help of a larynx-like sprayer. Inoculated plants were placed in a moist chamber at $28^{\circ} \mathrm{C}$, for the first $24 \mathrm{~h}$ in darkness, and were then transferred back to another moist chamber with a photoperiod of $12 \mathrm{~h}$ under fluorescent lights (Zhang et al. 2009). Disease severity was assessed at 5 days after inoculation. Diseased rice blades (approximately $6 \mathrm{~cm}$ long) were photographed, and the percentage of diseased leaf area was recorded and calculated as described by Fang and Dean (2000), to evaluate the virulence of the mutants. For microscopic observation of penetration and infectious hyphae expansion on rice tissue, excised leaf sheath of rice cultivar CO-39 was prepared as previously described (Kankanala et al. 2007; Koga et al. 2004) and was inoculated with conidia suspension $\left(1 \times 10^{4}\right.$ conidia $\left.\mathrm{ml}^{-1}\right)$ on the inner leaf-sheath cuticle cells. After 24, 48, and $72 \mathrm{~h}$ of incubation in a moistened plate, the chlorophyll-enriched plant parts in the leaf sheath were removed and the remaining three- to fourlayer-thick cells were utilized for microscopic visualizations. To observe the plant defense response, infected leaf-sheath cells were prepared as described above and were viewed under a Leica DMR microscope with ultraviolet radiation. The hostderived ROS staining was performed as described by Chi and associates (2009), using DAB (Sigma). All the experiments in this section were performed in three independent biological experiments, with three replicates in each experiment.

\section{Measurement of extracellular enzyme activity.}

Laccase activity on solid medium was carried out as described by Skamnioti and associates (2007) with little modification. A $5 \times 5$-mm hyphal tip plug was inoculated on CM supplemented with $0.2 \mathrm{mM}$ laccase substrate 2, 2'-azino-di-3-ethylbenzathia- zoline- 6-sulfonate (Sigma) for 3 days. For detection of peroxidase secretion in Moatfl mutant, a $5 \times 5-\mathrm{mm}$ hyphal tip plug was placed on CM containing 200 ppm CR for 5 days. The measurement of peroxidase and laccase activity in culture filtrate was performed as described by Chi and associates (2009). Three independent biological experiments were performed, with three replicates carried out in each test.

\section{Bioinformatics analysis.}

The full sequence of Moatfl was downloaded from the $M$. oryzae online database. Atf1 orthology sequences from different organisms were obtained from National Center for Biotechnology Information and the Broad Institute databases, using the BLAST algorithm (McGinnis and Madden 2004). Sequence alignments were performed using the Clustal_W program (Thompson et al. 1994), and the phylogenetic tree was viewed using the Mega3.0Beta program (Kumar et al. 2004). Signal peptide of peroxidase and laccase was predicted by the online program SignalP v3.0. Domain architecture was automatically provided from the European Bioinformatics Institute online database. Primers used in this study were designed by using Primer3 Input (version 0.4.0) and were commercially synthesized (Invitrogen Co., Shanghai, China).

\section{ACKNOWLEDGMENTS}

We gratefully acknowledge funding from a National Basic Research Program of China (grant no. 2006CB101901 to Z. Zhang), a Commonweal Specialized Research Fund of China Agriculture (200803008), two Natural Science Foundations of China (grant nos. 30771394 and 30971890 to $\mathrm{X}$. Zheng). We thank Z. Wang in Zhejiang University for providing plasmids pCB1532 and pCB1003. M. Gijzen (Agriculture and Agri-Food Canada, Canada) is especially acknowledged for helpful discussions and critical reading of the manuscript.

\section{LITERATURE CITED}

Abramovitch, R. B., Kim, Y. J., Chen, S., Dickman, M. B., and Martin, G. B. 2003. Pseudomonas type III effector AvrPtoB induces plant disease susceptibility by inhibition of host programmed cell death. EMBO (Eur. Mol. Biol. Organ.) J. 22:60-69.

Aguirre, J., Rios-Momberg, M., Hewitt, D., and Hansberg, W. 2005. Reactive oxygen species and development in microbial eukaryotes. Trends Microbiol. 13:111-118.

Alvarez, M. E., Pennell, R. I., Meijer, P. J., Ishikawa, A., Dixon, R. A., and Lamb, C. 1998. Reactive oxygen intermediates mediate a systemic signal network in the establishment of plant immunity. Cell 92:773-784.

Andersson, R. A., Koiv, V., Norman-Setterblad, C., and Pirhonen, M. 1999. Role of RpoS in virulence and stress tolerance of the plant pathogen Erwinia carotovora subsp. carotovora. Microbiology 145 (Pt 12):35473556.

Apel, K., and Hirt, H. 2004. Reactive oxygen species: metabolism, oxidative stress, and signal transduction. Annu. Rev. Plant Biol. 55:373-399.

Apostol, I., Heinstein, P. F., and Low, P. S. 1989. Rapid Stimulation of an oxidative burst during elicitation of cultured plant cells: Role in defense and signal transduction. Plant Physiol. 90:109-116.

Auh, C. K., and Murphy, T. M. 1995. Plasma membrane redox enzyme is involved in the synthesis of $\mathrm{O}^{2-}$ and $\mathrm{H}_{2} \mathrm{O}_{2}$ by Phytophthora elicitorstimulated rose cells. Plant Physiol. 107:1241-1247.

Bar-Nunn, N., Tal-Lev, A., Harel, E., and Mayer, A. M. 1988. Repression of laccase formation in Botrytis cinerea and its possible relation to phytopathogenicity. Phytochemistry 27:2505-2509.

Bedard, K., and Krause, K. H. 2007. The NOX family of ROS-generating NADPH oxidases: Physiology and pathophysiology. Physiol. Rev. 87:245-313.

Bolwell, G. P., Davies, D. R., Gerrish, C., Auh, C. K., and Murphy, T. M. 1998. Comparative biochemistry of the oxidative burst produced by rose and French bean cells reveals two distinct mechanisms. Plant Physiol. 116:1379-1385.

Bradley, D. J., Kjellbom, P., and Lamb, C. J. 1992. Elicitor- and woundinduced oxidative cross-linking of a proline-rich plant cell wall protein: A novel, rapid defense response. Cell 70:21-30.

Carroll, A., Sweigard, J., and Valent, B. 1994. Improved vectors for selecting resistance to hygromycin. Fungal Genet. Newsl. 41:22. 
Cessna, S. G., Sears, V. E., Dickman, M. B., and Low, P. S. 2000. Oxalic acid, a pathogenicity factor for Sclerotinia sclerotiorum, suppresses the oxidative burst of the host plant. Plant Cell 12:2191-2200.

Chen, J., Zheng, W., Zheng, S., Zhang, D., Sang, W., Chen, X., Li, G., Lu, G., and Wang, Z. 2008. Rac1 is required for pathogenicity and Chm1dependent conidiogenesis in rice fungal pathogen Magnaporthe grisea. PLoS Pathog. 4:e1000202.

Chi, M. H., Park, S. Y., Kim, S., and Lee, Y. H. 2009. A novel pathogenicity gene is required in the rice blast fungus to suppress the basal defenses of the host. PLoS Pathog. 5:e1000401.

Chisholm, S. T., Coaker, G., Day, B., and Staskawicz, B. J. 2006. Hostmicrobe interactions: Shaping the evolution of the plant immune response. Cell 124:803-814.

Cripps, C., Bumpus, J. A., and Aust, S. D. 1990. Biodegradation of azo and heterocyclic dyes by Phanerochaete chrysosporium. Appl. Environ. Microbiol. 56:1114-1118.

D'Autreaux, B., and Toledano, M. B. 2007. ROS as signalling molecules: Mechanisms that generate specificity in ROS homeostasis. Nat. Rev. Mol. Cell Biol. 8:813-824.

Dean, R. A., Talbot, N. J., Ebbole, D. J., Farman, M. L., Mitchell, T. K., Orbach, M. J., Thon, M., Kulkarni, R., Xu, J. R., Pan, H., Read, N. D., Lee, Y. H., Carbone, I., Brown, D., Oh, Y. Y., Donofrio, N., Jeong, J. S., Soanes, D. M., Djonovic, S., Kolomiets, E., Rehmeyer, C., Li, W., Harding, M., Kim, S., Lebrun, M. H., Bohnert, H., Coughlan, S., Butler, J., Calvo, S., Ma, L. J., Nicol, R., Purcell, S., Nusbaum, C., Galagan, J. E., and Birren, B. W. 2005. The genome sequence of the rice blast fungus Magnaporthe grisea. Nature 434:980-986.

Degols, G., and Russell, P. 1997. Discrete roles of the Spc1 kinase and the Atf1 transcription factor in the UV response of Schizosaccharomyces pombe. Mol. Cell Biol. 17:3356-3363.

Doke, N. 1983. Generation of superoxide anion by potato tuber protoplasts during the hypersensitive response to hyphal wall components of Phytophthora infestans and specific inhibition of the reaction by suppressors of hypersensitivity. Physiol. Plant Pathol. 23:359-367.

Doke, N. 1985. NADPH-dependent $\mathrm{O}^{2-}$ generation in membrane fractions isolated from wounded potato tubers inoculated with Phytophthora infestans. Physiol. Plant Pathol. 27:311-322.

Egan, M. J., Wang, Z. Y., Jones, M. A., Smirnoff, N., and Talbot, N. J. 2007. Generation of reactive oxygen species by fungal NADPH oxidases is required for rice blast disease. Proc. Natl. Acad. Sci. U.S.A. 104:11772-11777.

Fang, E. G., and Dean, R. A. 2000. Site-directed mutagenesis of the $\operatorname{magB}$ gene affects growth and development in Magnaporthe grisea. Mol. Plant-Microbe Interact. 13:1214-1227.

Gechev, T. S., and Hille, J. 2005. Hydrogen peroxide as a signal controlling plant programmed cell death. J. Cell Biol. 168:17-20.

Giles, S. S., Stajich, J. E., Nichols, C., Gerrald, Q. D., Alspaugh, J. A., Dietrich, F., and Perfect, J. R. 2006. The Cryptococcus neoformans catalase gene family and its role in antioxidant defense. Eukaryotic Cell 5:1447-1459.

Grant, J. J., and Loake, G. J. 2000. Role of reactive oxygen intermediates and cognate redox signaling in disease resistance. Plant Physiol. 124:21-29.

Grant, M., Brown, I., Adams, S., Knight, M., Ainslie, A., and Mansfield, J. 2000. The RPM1 plant disease resistance gene facilitates a rapid and sustained increase in cytosolic calcium that is necessary for the oxidative burst and hypersensitive cell death. Plant J. 23:441-450.

Hamer, J. E., Howard, R. J., Chumley, F. G., and Valent, B. 1988. A mechanism for surface attachment in spores of a plant pathogenic fungus. Science 239:288-290.

Howard, R. J., Ferrari, M. A., Roach, D. H., and Money, N. P. 1991. Penetration of hard substrates by a fungus employing enormous turgor pressures. Proc. Natl. Acad. Sci. U.S.A. 88:11281-11284.

Jeon, J., Goh, J., Yoo, S., Chi, M.-H., Choi, J., Rho, H.-S., Park, J., Han, S.-S., Kim, B. R., Park, S.-Y., Kim, S., and Lee, Y.-H. 2008. A putative MAP kinase kinase kinase, $M C K 1$, is required for cell wall integrity and pathogenicity of the rice blast fungus, Magnaporthe oryzae. Mol. Plant-Microbe Interact. 21:525-534.

Jones, J. D., and Dangl, J. L. 2006. The plant immune system. Nature 444:323-329.

Kankanala, P., Czymmek, K., and Valent, B. 2007. Roles for rice membrane dynamics and plasmodesmata during biotrophic invasion by the blast fungus. Plant Cell 19:706-724.

Kawasaki, L., Wysong, D., Diamond, R., and Aguirre, J. 1997. Two divergent catalase genes are differentially regulated during Aspergillus nidulans development and oxidative stress. J. Bacteriol. 179:32843292.

Kim, K. H., Willger, S. D., Park, S. W., Puttikamonkul, S., Grahl, N., Cho, Y., Mukhopadhyay, B., Cramer, R. A., Jr., and Lawrence, C. B. 2009. TmpL, a transmembrane protein required for intracellular redox ho- meostasis and virulence in a plant and an animal fungal pathogen. PLoS Pathog. 5:e1000653.

Koga, H., Dohi, K., Nakayachi, O., and Mori, M. 2004. A novel inoculation method of Magnaporthe grisea for cytological observation of the infection process using intact leaf sheaths of rice plants. Physiol. Mol. Plant Pathol. 64:67-72.

Kumar, S., Tamura, K., and Nei, M. 2004. MEGA3: Integrated software for molecular evolutionary genetics analysis and sequence alignment. Briefings Bioinf. 5:150-163.

Lamb, C., and Dixon, R. A. 1997. THE OXIDATIVE BURST IN PLANT DISEASE RESISTANCE. Annu. Rev. Plant Physiol. Plant Mol. Biol. 48:251-275.

Landschulz, W. H., Johnson, P. F., and McKnight, S. L. 1988. The leucine zipper: A hypothetical structure common to a new class of DNA binding proteins. Science 240:1759-1764.

Lanfranco, L., Novero, M., and Bonfante, P. 2005. The mycorrhizal fungus Gigaspora margarita possesses a $\mathrm{CuZn}$ superoxide dismutase that is up-regulated during symbiosis with legume hosts. Plant Physiol. 137:1319-1330.

Lev, S., Hadar, R., Amedeo, P., Baker, S. E., Yoder, O. C., and Horwitz, B. A. 2005. Activation of an AP1-like transcription factor of the maize pathogen Cochliobolus heterostrophus in response to oxidative stress and plant signals. Eukaryotic Cell 4:443-454.

Levine, A., Tenhaken, R., Dixon, R., and Lamb, C. 1994. $\mathrm{H}_{2} \mathrm{O}_{2}$ from the oxidative burst orchestrates the plant hypersensitive disease resistance response. Cell 79:583-593.

Li, J., Zhang, Z. G., Ji, R., Wang, Y. C., and Zheng, X. B. 2006. Hydrogen peroxide regulates elicitor PB90-induced cell death and defense in nonheading Chinese cabbage. Physiol. Mol. Plant Pathol. 67:220-230.

Lin, C.-H., Yang, S. L., and Chung, K.-R. 2009. The YAP1 homolog-mediated oxidative stress tolerance is crucial for pathogenicity of the necrotrophic fungus Alternaria alternata in citrus. Mol. Plant-Microbe Interact. 22:942-952.

McGinnis, S., and Madden, T. L. 2004. BLAST: At the core of a powerful and diverse set of sequence analysis tools. Nucleic Acids Res. 32:W2025 .

Mei, C., Qi, M., Sheng, G., and Yang, Y. 2006. Inducible overexpression of a rice allene oxide synthase gene increases the endogenous jasmonic acid level, $P R$ gene expression, and host resistance to fungal infection. Mol. Plant-Microbe Interact. 19:1127-1137.

Mellersh, D. G., Foulds, I. V., Higgins, V. J., and Heath, M. C. 2002. $\mathrm{H}_{2} \mathrm{O}_{2}$ plays different roles in determining penetration failure in three diverse plant-fungal interactions. Plant J. 29:257-268.

Mileski, G. J., Bumpus, J. A., Jurek, M. A., and Aust, S. D. 1988. Biodegradation of pentachlorophenol by the white rot fungus Phanerochaete chrysosporium. Appl. Environ. Microbiol. 54:2885-2889.

Miller, R. A., and Britigan, B. E. 1997. Role of oxidants in microbial pathophysiology. Clin. Microbiol. Rev. 10:1-18.

Mittler, R. 2002. Oxidative stress, antioxidants and stress tolerance. Trends Plant Sci. 7:405-410.

Molina, L., and Kahmann, R. 2007. An Ustilago maydis gene involved in $\mathrm{H}_{2} \mathrm{O}_{2}$ detoxification is required for virulence. Plant Cell 19:2293-2309.

Morre, D..J. 2002. Preferential inhibition of the plasma membrane NADH oxidase (NOX) activity by diphenyleneiodonium chloride with NADPH as donor. Antioxid. Redox Signaling 4:207-212.

Moye-Rowley, W. S. 2003. Regulation of the transcriptional response to oxidative stress in fungi: Similarities and differences. Eukaryotic Cell 2:381-389.

Nathues, E., Joshi, S., Tenberge, K. B., von den Driesch, M., Oeser, B., Baumer, N., Mihlan, M., and Tudzynski, P. 2004. CPTF1, a CREB-like transcription factor, is involved in the oxidative stress response in the phytopathogen Claviceps purpurea and modulates ROS level in its host Secale cereale. Mol. Plant-Microbe Interact. 17:383-393.

Navarro, R. E., Stringer, M. A., Hansberg, W., Timberlake, W. E., and Aguirre, J. 1996. catA, a new Aspergillus nidulans gene encoding a developmentally regulated catalase. Curr. Genet. 29:352-359.

Nguyen, A. N., Lee, A., Place, W., and Shiozaki, K. 2000. Multistep phosphorelay proteins transmit oxidative stress signals to the fission yeast stress-activated protein kinase. Mol. Biol. Cell 11:1169-1181.

Niemann, G., Van Der Kerk, A, Niessen, M., and Versluis, K. 1991. Free and cell wall-bound phenolics and other constituents from healthy and fungus infected carnation (Dianthus caryophilus L.) stems. Physiol. Mol. Plant Pathol. 38:417-432.

Nurnberger, T., Brunner, F., Kemmerling, B., and Piater, L. 2004. Innate immunity in plants and animals: Striking similarities and obvious differences. Immunol. Rev. 198:249-266.

Ono, E., Wong, H. L., Kawasaki, T., Hasegawa, M., Kodama, O., and Shimamoto, K. 2001. Essential role of the small GTPase Rac in disease resistance of rice. Proc. Natl. Acad. Sci. U.S.A. 98:759-764

Qiu, D., Xiao, J., Ding, X., Xiong, M., Cai, M., Cao, Y., Li, X., Xu, C., 
and Wang, S. 2007. OsWRKY13 mediates rice disease resistance by regulating defense-related genes in salicylate- and jasmonate-dependent signaling. Mol. Plant-Microbe Interact. 20:492-499.

Quinn, J., Findlay, V. J., Dawson, K., Millar, J. B., Jones, N., Morgan, B. A., and Toone, W. M. 2002. Distinct regulatory proteins control the graded transcriptional response to increasing $\mathrm{H}(2) \mathrm{O}(2)$ levels in fission yeast Schizosaccharomyces pombe. Mol. Biol. Cell 13:805-816.

Ram, A. F., Wolters, A., Ten Hoopen, R., and Klis, F. M. 1994. A new approach for isolating cell wall mutants in Saccharomyces cerevisiae by screening for hypersensitivity to calcofluor white. Yeast 10:10191030 .

Sakamoto, K., Iwashita, K., Yamada, O., Kobayashi, K., Mizuno, A., Akita, O., Mikami, S., Shimoi, H., and Gomi, K. 2009. Aspergillus oryzae atfA controls conidial germination and stress tolerance. Fungal Genet. Biol. 46:887-897.

Sambrook, J., Fritsch, E. F., and Maniatis, T. 1989. Molecular Cloning: A Laboratory Manual. Cold Spring Harbor Laboratory Press. Cold Spring Harbor, NY, U.S.A

Shiozaki, K., and Russell, P. 1996. Conjugation, meiosis, and the osmotic stress response are regulated by Spc1 kinase through Atf1 transcription factor in fission yeast. Genes Dev. 10:2276-2288.

Simon-Plas, F., Elmayan, T., and Blein, J. P. 2002. The plasma membrane oxidase NtrbohD is responsible for AOS production in elicited tobacco cells. Plant J. 31:137-147.

Skamnioti, P., Henderson, C., Zhang, Z., Robinson, Z., and Gurr, S. J 2007. A novel role for catalase B in the maintenance of fungal cell-wall integrity during host invasion in the rice blast fungus Magnaporthe grisea. Mol. Plant-Microbe Interact. 20:568-580.

Takemoto, D., Tanaka, A., and Scott, B. 2007. NADPH oxidases in fungi: Diverse roles of reactive oxygen species in fungal cellular differentiation. Fungal Genet. Biol. 44:1065-1076.

Talbot, N. J. 2003. On the trail of a cereal killer: Exploring the biology of Magnaporthe grisea. Annu. Rev. Microbiol. 57:177-202.

Tanaka, A., Christensen, M. J., Takemoto, D., Park, P., and Scott, B. 2006. Reactive oxygen species play a role in regulating a fungus-perennial ryegrass mutualistic interaction. Plant Cell 18:1052-1066.

Tanaka, A., Takemoto, D., Hyon, G. S., Park, P., and Scott, B. 2008. NoxA activation by the small GTPase RacA is required to maintain a mutualistic symbiotic association between Epichloe festucae and perennial ryegrass. Mol. Microbiol. 68:1165-1178.

Tanaka, N., Che, F.-S., Watanabe, N., Fujiwara, S., Takayama, S., and Isogai, A. 2003. Flagellin from an incompatible strain of Acidovorax avenae mediates $\mathrm{H}_{2} \mathrm{O}_{2}$ generation accompanying hypersensitive cell death and expression of $P A L, C h t-1$, and $P B Z 1$, but not of Lox in rice. Mol. Plant-Microbe Interact. 16:422-428.

Thompson, J. D., Higgins, D. G., and Gibson, T. J. 1994. CLUSTAL W: Improving the sensitivity of progressive multiple sequence alignment through sequence weighting, position-specific gap penalties and weight matrix choice. Nucleic Acids Res. 22:4673-4680.

Toone, W. M., and Jones, N. 1999. AP-1 transcription factors in yeast. Curr. Opin. Genet. Dev. 9:55-61.
Torres, M. A., and Dangl, J. L. 2005. Functions of the respiratory burst oxidase in biotic interactions, abiotic stress and development. Curr. Opin. Plant Biol. 8:397-403.

Torres, M. A., Dangl, J. L., and Jones, J. D. 2002. Arabidopsis gp91phox homologues AtrbohD and AtrbohF are required for accumulation of reactive oxygen intermediates in the plant defense response. Proc. Natl. Acad. Sci. U.S.A. 99:517-522.

Torres, M. A., Jones, J. D., and Dangl, J. L. 2005. Pathogen-induced, NADPH oxidase-derived reactive oxygen intermediates suppress spread of cell death in Arabidopsis thaliana. Nat. Genet. 37:1130-1134.

Wilkinson, M. G., Samuels, M., Takeda, T., Toone, W. M., Shieh, J. C Toda, T., Millar, J. B., and Jones, N. 1996. The Atf1 transcription factor is a target for the Sty1 stress-activated MAP kinase pathway in fission yeast. Genes Dev. 10:2289-2301.

Wong, H. L., Pinontoan, R., Hayashi, K., Tabata, R., Yaeno, T., Hasegawa, K., Kojima, C., Yoshioka, H., Iba, K., Kawasaki, T., and Shimamoto, K. 2007. Regulation of rice NADPH oxidase by binding of Rac GTPase to its N-terminal extension. Plant Cell 19:4022-4034.

Wood, P. J., and Fulcher, R. G. 1983. Dye interactions. A basis for specific detection and histochemistry of polysaccharides. J. Histochem. Cytochem. 31:823-826.

Xu, J. R. 2000. Map kinases in fungal pathogens. Fungal Genet. Biol. 31:137-152.

Xu, J. R., Staiger, C. J., and Hamer, J. E. 1998. Inactivation of the mitogen-activated protein kinase Mps1 from the rice blast fungus prevents penetration of host cells but allows activation of plant defense responses. Proc. Natl. Acad. Sci. U.S.A. 95:12713-12718.

Yoshioka, H., Bouteau, F., and Kawano, T. 2008. Discovery of oxidative burst in the field of plant immunity: Looking back at the early pioneering works and towards the future development. Plant Signal Behav. 3:153-155.

Yoshioka, H., Numata, N., Nakajima, K., Katou, S., Kawakita, K. Rowland, O., Jones, J. D., and Doke, N. 2003. gp91phox homologs NbrbohA and NbrbohB participate in $\mathrm{H}_{2} \mathrm{O}_{2}$ accumulation and resistance to Phytophthora infestans. Plant Cell 15:706-718.

Zhang, H., Zhao, Q., Liu, K., Zhang, Z., Wang, Y., and Zheng, X. 2009. MgCRZ1, a transcription factor of Magnaporthe grisea, controls growth, development and is involved in full virulence. FEMS (Fed. Eur. Microbiol. Soc.) Microbiol. Lett. 293:160-169.

\section{AUTHOR-RECOMMENDED INTERNET RESOURCES}

Broad Institute's Fungal Genome Initiative database: www.broadinstitute.org/science/projects/fungal-genome-initiative/ current-fgi-sequence-projects

Broad Institute's M. oryzae genome database: www.broadinstitute.org/ annotation/genome/magnaporthe_grisea/MultiHome.html

European Bioinformatics Institute database: www.ebi.ac.uk

National Center for Biotechnology Information Blast database: www.ncbi.nlm.nih.gov/BLAST 